\title{
Thermal Development Test of the NEXT PM1 Ion Engine
}

John R. Anderson and John S. Snyder

Jet Propulsion Laboratory, Pasadena, California

Jonathan L. Van Noord and George C. Soulas

Glenn Research Center, Cleveland, Ohio 


\section{NASA STI Program . . . in Profile}

Since its founding, NASA has been dedicated to the advancement of aeronautics and space science. The NASA Scientific and Technical Information (STI) program plays a key part in helping NASA maintain this important role.

The NASA STI Program operates under the auspices of the Agency Chief Information Officer. It collects, organizes, provides for archiving, and disseminates NASA's STI. The NASA STI program provides access to the NASA Aeronautics and Space Database and its public interface, the NASA Technical Reports Server, thus providing one of the largest collections of aeronautical and space science STI in the world. Results are published in both non-NASA channels and by NASA in the NASA STI Report Series, which includes the following report types:

- TECHNICAL PUBLICATION. Reports of completed research or a major significant phase of research that present the results of NASA programs and include extensive data or theoretical analysis. Includes compilations of significant scientific and technical data and information deemed to be of continuing reference value. NASA counterpart of peer-reviewed formal professional papers but has less stringent limitations on manuscript length and extent of graphic presentations.

- TECHNICAL MEMORANDUM. Scientific and technical findings that are preliminary or of specialized interest, e.g., quick release reports, working papers, and bibliographies that contain minimal annotation. Does not contain extensive analysis.

- CONTRACTOR REPORT. Scientific and technical findings by NASA-sponsored contractors and grantees.
- CONFERENCE PUBLICATION. Collected papers from scientific and technical conferences, symposia, seminars, or other meetings sponsored or cosponsored by NASA.

- SPECIAL PUBLICATION. Scientific, technical, or historical information from NASA programs, projects, and missions, often concerned with subjects having substantial public interest.

- TECHNICAL TRANSLATION. Englishlanguage translations of foreign scientific and technical material pertinent to NASA's mission.

Specialized services also include creating custom thesauri, building customized databases, organizing and publishing research results.

For more information about the NASA STI program, see the following:

- Access the NASA STI program home page at http://www.sti.nasa.gov

- E-mail your question via the Internet to help@ sti.nasa.gov

- Fax your question to the NASA STI Help Desk at $443-757-5803$

- Telephone the NASA STI Help Desk at 443-757-5802

- Write to: NASA Center for AeroSpace Information (CASI) 7115 Standard Drive Hanover, MD 21076-1320 
NASA/TM-2010-216914

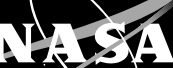

Thermal Development Test of the NEXT PM1 Ion Engine

John R. Anderson and John S. Snyder

Jet Propulsion Laboratory, Pasadena, California

Jonathan L. Van Noord and George C. Soulas

Glenn Research Center, Cleveland, Ohio

Prepared for the

43rd Joint Propulsion Conference

cosponsored by AIAA, ASME, SAE, and ASEE

Cincinnati, Ohio, July 8-11, 2007

National Aeronautics and

Space Administration

Glenn Research Center

Cleveland, Ohio 44135 


\section{Acknowledgments}

The Thermal Development Test was successfully accomplished through the efforts of a multiorganizational team. The work was performed under the NASA's Evolutionary Xenon Thruster (NEXT) Project, led by the NASA Glenn Research Center (GRC), with Scott Benson as the Project Manager and Mike Patterson as the Principal Investigator. Kevin McCormick, and Daniel Herman of GRC spent a significant amount of time at the Jet Propulsion Laboratory (JPL) during the testing described herein and were instrumental in performing this work. Andy Hoskins of Aerojet provided support for the test. At JPL, Allison Owens and Ray Swindlehurst were responsible for designing, configuring, and operating the test facility. Mike Pauken and Phil Stevens helped in the design and measurement of the MLI heat flux coupon boxes. The radiometer for coupon calibration was supplied by JPL's Environmental Test Laboratory and support was provided by Doug Perry. Paul Giuliano, a JPL summer student, helped set up and perform the heat flux coupon calibration. Jack Garbett, a JPL summer student, assisted with setting up the facility for thermocouple measurements. Their efforts and contributions are appreciated. The research described in this paper was carried out by the Jet Propulsion Laboratory, California Institute of Technology, under a contract with the National Aeronautics and Space Administration.

Level of Review: This material has been technically reviewed by technical management.

Available from

NASA Center for Aerospace Information 7115 Standard Drive

Hanover, MD 21076-1320
National Technical Information Service 5301 Shawnee Road Alexandria, VA 22312 


\title{
Thermal Development Test of the NEXT PM1 Ion Engine
}

\author{
John R. Anderson and John S. Snyder \\ Jet Propulsion Laboratory \\ Pasadena, California 91109 \\ Jonathan L. Van Noord and George C. Soulas \\ National Aeronautics and Space Administration \\ Glenn Research Center \\ Cleveland, Ohio 44135
}

\begin{abstract}
NASA's Evolutionary Xenon Thruster (NEXT) is a next-generation high-power ion propulsion system under development by NASA as a part of the In-Space Propulsion Technology Program. NEXT is designed for use on robotic exploration missions of the solar system using solar electric power. Potential mission destinations that could benefit from a NEXT Solar Electric Propulsion (SEP) system include inner planets, small bodies, and outer planets and their moons. This range of robotic exploration missions generally calls for ion propulsion systems with deep throttling capability and system input power ranging from 0.6 to $25 \mathrm{~kW}$, as referenced to solar array output at 1 Astronomical Unit (AU). Thermal development testing of the NEXT prototype model 1 (PM1) was conducted at JPL to assist in developing and validating a thruster thermal model and assessing the thermal design margins. NEXT PM1 performance prior to, during and subsequent to thermal testing are presented. Test results are compared to the predicted hot and cold environments expected missions and the functionality of the thruster for these missions is discussed.
\end{abstract}

\section{Nomenclature}

$J_{b} \quad$ beam current (A)

$J_{d} \quad$ discharge current (A)

$J_{d c u t} \quad$ discharge cut back current (A)

$J_{d h}$

discharge cathode heater current $(\mathrm{A})$

neutralizer cathode heater current $(\mathrm{A})$

neutralizer keeper current (A)

cathode flow rate $(\mathrm{sccm})$

main flow rate $(\mathrm{sccm})$

neutralizer flow rate $(\mathrm{sccm})$

accelerator grid voltage (V)

beam voltage $(\mathrm{V})$

\section{Introduction}

$\mathrm{N}$

ASA's Evolutionary Xenon Thruster (NEXT) ${ }^{1-3}$ is a next-generation high-power ion propulsion system under development by NASA. The propulsion system effort includes thruster ${ }^{4}$, power processing unit ${ }^{5}$, propellant management system ${ }^{6}$, gimbal ${ }^{7}$, and some digital control interface unit ${ }^{8}$ development. The NEXT program is led by GRC and supported by JPL, Aerojet and L-3 Communications Electron Technologies, Inc., with participation by Applied Physics Laboratory, University of Michigan and Colorado State University, as a part of the In-Space Propulsion Technology Program. NEXT is designed for use on robotic exploration missions of the solar system using solar electric power. Potential mission destinations that could benefit from a NEXT Solar Electric Propulsion 
(SEP) system include inner planets, small bodies, and outer planets and their moons $\mathrm{s}^{9-11}$. This range of robotic exploration missions generally calls for ion propulsion systems with deep throttling capability and system input power ranging from 0.6 to $25 \mathrm{~kW}$, as referenced to solar array output at 1 Astronomical Unit (AU). The NEXT ion engine is the latest generation ion thruster; it is a $7-\mathrm{kW}, 36-\mathrm{cm}$-beam-diameter thruster with significant heritage to the 2.3-kW, 30-cm-beam-diameter NSTAR ion thruster that successfully flew on the Deep Space 1 mission $^{12}$. In addition, NSTAR ion thrusters are scheduled for launch on the DAWN spacecraft scheduled for launch in $2007^{13}$.

The NEXT thermal development test was conducted to aid in developing and validating a thermal mode ${ }^{14}$ for the thruster. The thermal model consists of a plasma model which is used to estimate the heat flux to thruster components as a function of the thruster operating point. The estimated heat flux due to the plasma and external heat fluxes obtained from mission analysis are input to a NEXT thermal model produced using a commercial software package. The model built with the commercial software is used to predict thruster component temperatures using thruster thermal conductivity and surface optical properties. The NEXT ion engine thermal model was correlated with the data from the thermal development test and predicts temperatures within $10{ }^{\circ} \mathrm{C}$ for most thruster components.

During the thermal development test data were recorded to document key thruster temperatures as a function of thruster operating conditions and thermal environment. Information obtained from this test was also used to determine the reference temperature location and test conditions for subsequent thermal vacuum testing.

\section{A.Test Objectives}

The NEXT thermal development test had two major objectives. One was to document key thruster temperatures as a function of thruster operating condition and thermal environments that would be encountered during a typical mission. These data were used to develop and validate the NEXT thermal model. The second objective was to select the reference temperature location.

The first objective required testing the thruster at selected points spanning the thruster throttle range under cold, ambient and hot environmental conditions. Testing was also required to ascertain thruster and thruster component temperature margins under worst case thermal loads identified from mission analysis. In addition testing to determine the external heat load required to first reach a thruster component temperature limit was desired. In order to provide additional data for model validation, the thruster was heated using the cathode and neutralizer heaters under cold conditions.

The second objective included selection of the thruster reference temperature location for flight and ground test use. The thermal development test was also used to determine the appropriate test conditions for the subsequent thermal vacuum test (TVT); this included cold soak temperatures and heat flux required for hot testing.

\section{B.Temperature Limits}

Temperature limits for critical thruster components were specified for the magnets, propellant isolator, wire harnesses and also at the candidate temperature reference locations - thruster gimbal pads- used during the thermal development test. The do-not-exceed low temperature limit for the thruster was set at $-230{ }^{\circ} \mathrm{C}$; however, the propellant lines and propellant isolators were required to be above $-120^{\circ} \mathrm{C}$ during thruster starts. The do-not-exceed upper temperature limit was $360^{\circ} \mathrm{C}$ for the magnets, $265^{\circ} \mathrm{C}$ for the propellant isolators and was $260^{\circ} \mathrm{C}$ for the internal thruster wire harness. The external wire harness was originally limited to $150^{\circ} \mathrm{C}$ due to the material rating of the harness jacketing material; the limit was subsequently increased to $200{ }^{\circ} \mathrm{C}$ to allow environmental testing ${ }^{15}$ at higher temperatures after it was determined that operation at temperatures up to $200{ }^{\circ} \mathrm{C}$ - for the duration of the thermal development test and environmental testing — would not damage the harness.

\section{C.Thruster Operating Points}

Testing was conducted using laboratory power supplies. The thruster operating points used during the thermal development test are listed in Table 1. Nine operating conditions were run during the functional and thermal testing. The table lists the control settings for these operating points, as well as those for cathode ignition.

Seven parameters are controlled during normal thruster operation. The propellant flow rates to the discharge chamber $\left(\dot{m}_{m}\right)$, cathode $\left(\dot{m}_{c}\right)$, and neutralizer $\left(\dot{m}_{n}\right)$ are controlled. Ion optics parameters-beam current $(\mathrm{Jb})$, beam voltage $(\mathrm{Vb})$, and accelerator grid voltage $(\mathrm{Va})$ - are set to maintain the fraction of propellant accelerated to high speed, to provide the desired kinetic energy to the beam ions, and to prevent electron backstreaming. The neutralizer keeper current (Jnk) is set to maintain efficient neutralizer operation and to prevent the neutralizer from extinguishing during recycles. 
Two other parameters are controlled during thruster starts. The discharge cathode (Jdh) and neutralizer heater current (Jnh) are maintained at the specified set point to heat the cathodes to thermionic emission temperatures. Once cathode or neutralizer ignition has occurred, the heater current to that component is turned off.

In addition to the control parameters two other parameters-discharge current (Jd) and discharge cut back current (Jdcut) - are also listed in Table 1. During normal thruster operation, the discharge current is varied to provide the desired beam current. Nominal discharge currents are listed in the table to provide a reasonable set point during thruster starts prior to applying high voltage for beam extraction. The discharge current cut back is used during recycles, where the discharge current is cut back to a low value to avoid over-current conditions while the high voltage is being ramped up. Because each of the thermal development test points has a unique combination of beam current $\mathrm{Jb}$ and beam voltage $\mathrm{Vb}$ these variables are used to identify the operating point throughout this paper.

Table 1. NEXT PM1 Throttle Table.

\begin{tabular}{|c|c|c|c|c|c|c|c|c|c|c|}
\hline $\begin{array}{c}\text { Control } \\
\text { Parameter }\end{array}$ & Ignition & $\begin{array}{c}\text { Discharge } \\
\text { Only }\end{array}$ & $\begin{array}{c}\text { TDT } \\
1\end{array}$ & $\begin{array}{c}\text { TDT } \\
2\end{array}$ & $\begin{array}{c}\text { TDT } \\
3\end{array}$ & $\begin{array}{c}\text { TDT } \\
4\end{array}$ & $\begin{array}{c}\text { TDT } \\
5\end{array}$ & $\begin{array}{c}\text { TDT } \\
6\end{array}$ & $\begin{array}{c}\text { TDT } \\
7\end{array}$ & $\begin{array}{c}\text { TDT } \\
8\end{array}$ \\
\hline Jnh (A) & 8.5 & - & - & - & - & - & - & - & - & - \\
\hline Jnk (A) & 3.0 & 3.0 & 3.0 & 3.0 & 3.0 & 3.0 & 3.0 & 3.0 & 3.0 & 3.0 \\
\hline $\mathrm{Jdh}(\mathrm{A})$ & 8.5 & - & - & - & - & - & - & - & - & - \\
\hline $\mathrm{Jd}(\mathrm{A})$ & 9.0 & 9.0 & $8.0^{\mathrm{a}}$ & $9.5^{\mathrm{a}}$ & $8.8^{\mathrm{a}}$ & $8.4^{\mathrm{a}}$ & $14.7^{\mathrm{a}}$ & $13.9^{\mathrm{a}}$ & $20.6^{\mathrm{a}}$ & $18.9^{\mathrm{a}}$ \\
\hline $\mathrm{Jdcut}(\mathrm{A})$ & - & - & 8.4 & 8.4 & 8.4 & 8.4 & 8.4 & 8.4 & 8.4 & 8.4 \\
\hline $\mathrm{Jb}(\mathrm{A})$ & - & - & 1.00 & 1.20 & 1.20 & 1.20 & 2.00 & 2.00 & 3.52 & 3.52 \\
\hline $\mathrm{Vb}(\mathrm{V})$ & - & - & 275 & 679 & 1179 & 1800 & 1179 & 1800 & 1179 & 1800 \\
\hline $\mathrm{Va}(\mathrm{V})$ & - & - & -500 & -115 & -200 & -210 & -200 & -210 & -200 & -210 \\
\hline$\dot{m}_{m}(\mathrm{sccm})$ & 14.23 & 14.23 & 12.32 & 14.23 & 14.23 & 14.23 & 25.79 & 25.79 & 49.64 & 49.64 \\
\hline$\dot{m}_{c}(\mathrm{sccm})$ & 3.57 & 3.57 & 3.52 & 3.57 & 3.57 & 3.57 & 3.87 & 3.87 & 4.87 & 4.87 \\
\hline$\dot{m}_{n}(\mathrm{sccm})$ & 6.00 & 6.00 & 3.00 & 3.00 & 3.00 & 3.00 & 2.50 & 2.50 & 4.01 & 4.01 \\
\hline
\end{tabular}

${ }^{a}$ Nominal Value; discharge current is adjusted to maintain a constant beam current.

\section{Test Hardware and Facilities}

\section{A.Thruster}

The thruster used in the thermal development test was the first 36-cm-beam-diameter prototype model (PM1) thruster fabricated by Aerojet ${ }^{4}$ for GRC under the NEXT project. The thruster is capable of operation over a wide power envelope, from beam currents and voltages of $1.0 \mathrm{~A}, 275 \mathrm{~V}$ at the low end to $3.52 \mathrm{~A}$ and $1800 \mathrm{~V}$ at the high end of the throttle range. The PM1 thruster was acceptance tested at $\mathrm{GRC}^{16}$ prior to shipping to JPL for thermal and environmental testing.

The NEXT PM1 thruster used for the thermal development test was instrumented with 34 thermocouples. The thermocouple locations were chosen based on preliminary thermal modeling and to obtain data for model validation. Twenty thermocouples were attached to high voltage components; seven were on magnet retainer rings, four were spot welded to the outside of the discharge chamber, three were on the ion optics, two were attached to the discharge cathode assembly, three were on wire harnesses and one was attached to a propellant isolator. Fourteen thermocouples were attached to low voltage surfaces; five were located at various locations on the plasma screen, three were mounted on the front mask, two were placed on the neutralizer assembly, one was on the neutralizer harness and one was spot welded to each of the three gimbal pads. These thermocouples were installed on PM1 prior to shipping to JPL. A schematic showing the locations of thermocouples used on PM1 during the thermal development test is provided in Figure 1. Thermocouple azimuthal locations may vary from that shown in Figure 1; the azimuthal angle is specified when viewing the rear plasma screen with the neutralizer located at 12 o'clock. In addition to the thruster thermocouples, thermocouples were also mounted on the gimbal flexures that interfaced between the PM1 gimbal pads and the thruster support structure during the thermal development test.

\section{B.Data Acquisition and Power Supply Control System}

The thermal development test was performed using laboratory power supplies. These power supplies were controlled by data acquisition and control software. The data acquisition system uses modules to read thruster 
currents, voltages, flow rates and temperatures; facility pressure and temperatures are also measured. The flow meters, voltage dividers and current shunts used to measure thruster data were calibrated prior to the thermal development test. The data acquisition software records thruster and facility data at a user specified rate. Typically data was recorded once a minute; however, during thruster starts or when thruster parameters were being varied the rate was often changed to once every ten seconds. The software used to record data was also used to control thruster power supplies and flow rates. The thruster operator could input the desired power supply and flow rate set points. Once the set points were entered the software made the appropriate adjustments to control the thruster operating parameters at the specified conditions.

\section{C.Thruster Test Facility}

The thermal development test was conducted in the patio chamber facility at the Jet Propulsion Laboratory. The $3 \mathrm{~m}$ diameter by $8.6 \mathrm{~m}$ long vacuum chamber had 9 active cyropumps for this test. With the vacuum chamber configuration used for the thermal development test the effective pumping speed was as high as 160,000 1/s. To minimize facility backsputter rates the interior of the vacuum facility is lined with graphite panels. Diagnostic equipment_ExB probe and Faraday probes_-were installed in the vacuum chamber.

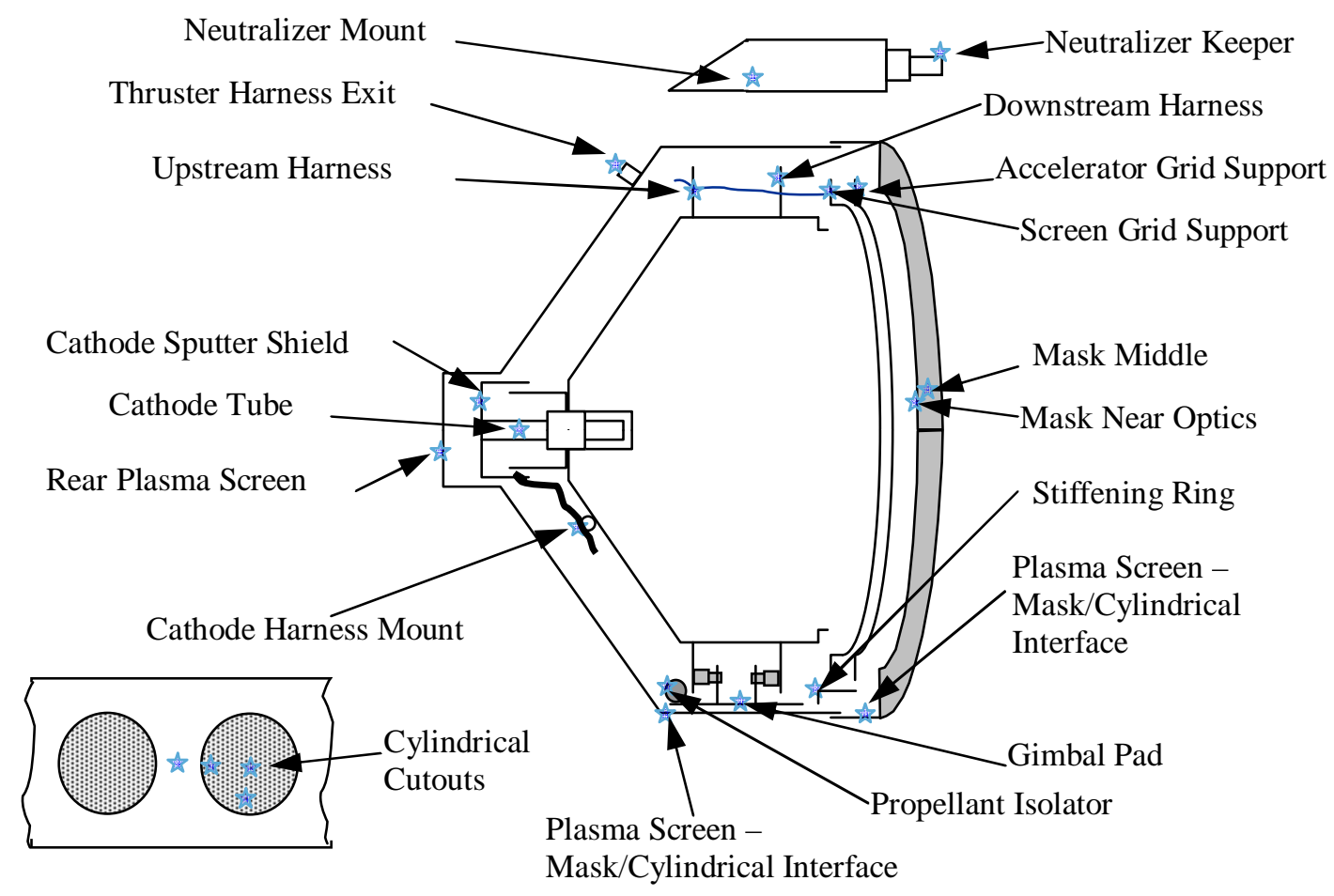

Figure 1. NEXT PM1 Thermocouple Locations.

NEXT PM1 was installed in a $1.2 \mathrm{~m}$ diameter by $1.0 \mathrm{~m}$ long thermal shroud as shown in Figure 2 . The downstream end of the thermal shroud was located $6.2 \mathrm{~m}$ from the downstream end of the vacuum facility. The thruster was mounted inside the shroud with the neutralizer keeper orifice plate located $5.7 \mathrm{~cm}$ from the downstream end of the shroud.

The shroud could be actively cooled with liquid nitrogen and also had eight heat lamps installed inside it to provide external heat flux to the thruster. The heat lamps were installed parallel to the thruster axis. The lamps were spaced 45 degrees apart azimuthally and aligned axially along the length of the thruster with one end of the lamp even with the front mask of PM1. The heat lamp controller was set up to vary the power to the lamps as required to maintain a control thermocouple at constant temperature set point.

In order to measure the heat flux to the thruster, heat flux coupons were developed for this test. The heat flux coupons consisted of painted aluminum sheet metal installed in a multi-layer insulation box with a $1 \mathrm{x} 1 \mathrm{~cm}$ aperture to allow external radiation to impinge on the aluminum. Due to variations in the dimensions and uncertainties in the 
optical properties of the surfaces, the heat flux coupons were calibrated using a radiometer as a standard. The calibration relates the incoming heat flux to the aluminum coupon temperature. Two heat flux coupons were used to monitor the thermal radiation to the thruster and a third coupon temperature was used to control the heat lamps. In this configuration the control parameter for hot environmental testing was effectively the flux to the engine from the environment, rather than the thruster reference location temperature. The top heat flux coupon was located $0.04 \mathrm{~m}$ above the neutralizer housing and $0.1 \mathrm{~m}$ behind the neutralizer keeper orifice plate. The bottom rear heat flux coupon was located $0.05 \mathrm{~m}$ below the thruster and $0.24 \mathrm{~m}$ behind the front mask. The bottom front heat flux coupon, used to control the heat lamps, was placed $0.05 \mathrm{~m}$ below the thruster and $0.12 \mathrm{~m}$ behind the front mask. The top heat flux sensor is shown in Figure 3 and the bottom heat flux sensors are shown in Figure 4.

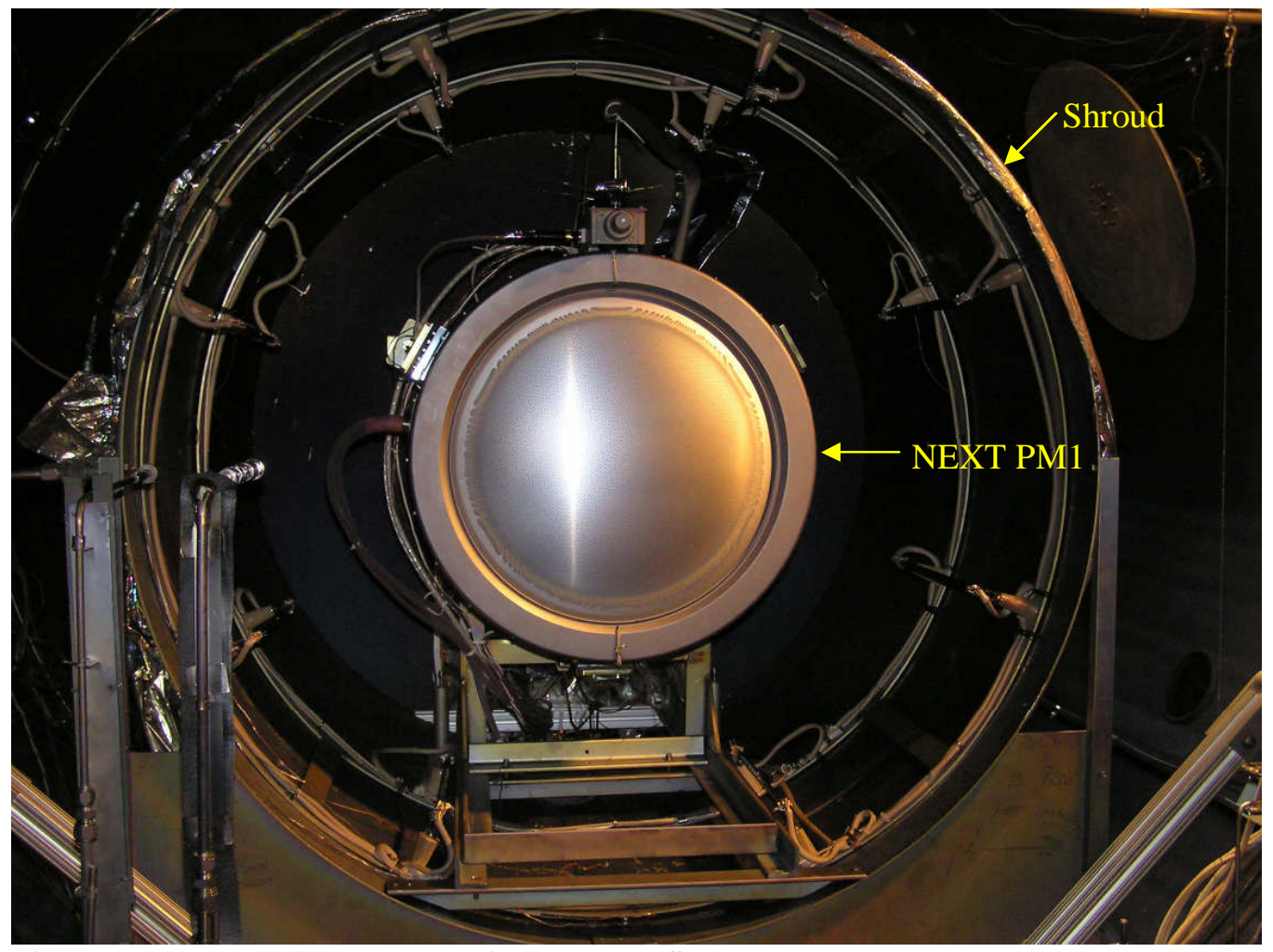

Figure 2. NEXT PM1 Installed Inside Thermal Shroud.

The shroud was equipped with a door made of multi-layer insulation. This door was opened during thruster operation; however, it could be closed to minimize thermal interaction with the vacuum facility during cold soak or hot soak when the thruster was not operating.

The shroud was equipped with 14 thermocouples used to monitor the thermal environment surrounding the thruster. Ten thermocouples were mounted at various axial and azimuthal locations on the interior cylindrical wall and two thermocouples were attached to the back wall of the shroud. One thermocouple was attached to the thruster support structure and one was attached to the tubing used to provide LN2 to cool the shroud. In addition to the shroud thermocouples other facility temperatures were monitored during the thermal development test. Thermocouples were located behind the graphite liner at the downstream end of the vacuum chamber as well as additional thermocouples on the side wall, on the ExB probe structure and on the cryopumps.

Double-to-single ion current ratios could be measured by an ExB probe mounted in the chamber $5.1 \mathrm{~m}$ downstream of the thruster. The ExB probe was aligned so that the probe collimator accepted beam ions from a $0.1 \mathrm{~m}$ diameter region at the center of the thruster.

Beam current density profiles could be measured by two Faraday probes. The Faraday probes were installed on a stage that allowed them to translate through the thruster plume at axial distances between $0.045 \mathrm{~m}$ and $0.55 \mathrm{~m}$ downstream of the thruster. The probes were mounted $8.7 \mathrm{~cm}$ apart and aligned so that they sweep through the same plane when they collect ions. Both probes collected ion current on a circular button which was surrounded by a guard ring. 


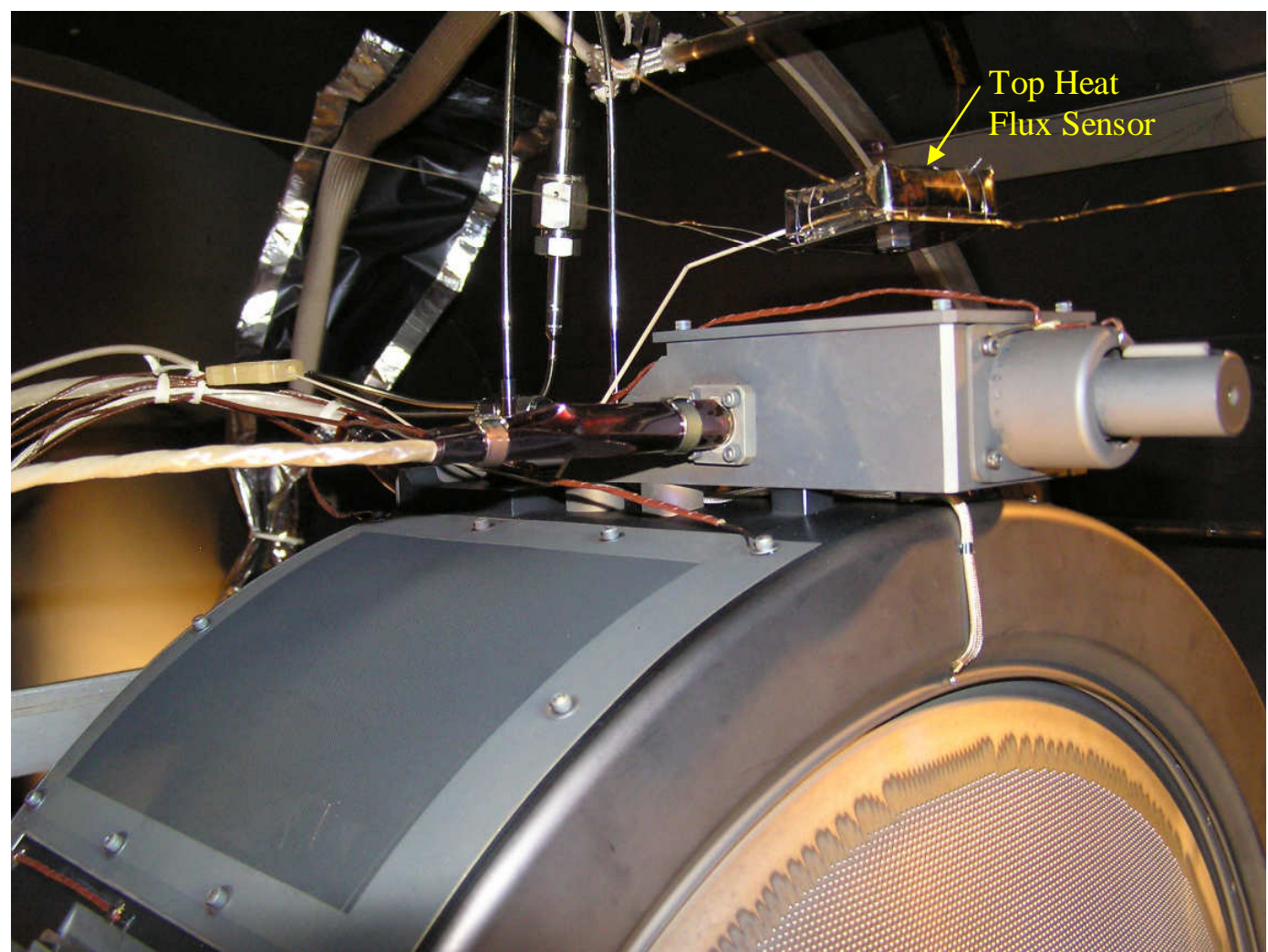

Figure 3. NEXT PM1 Neutralizer and Top Heat Flux Sensor.

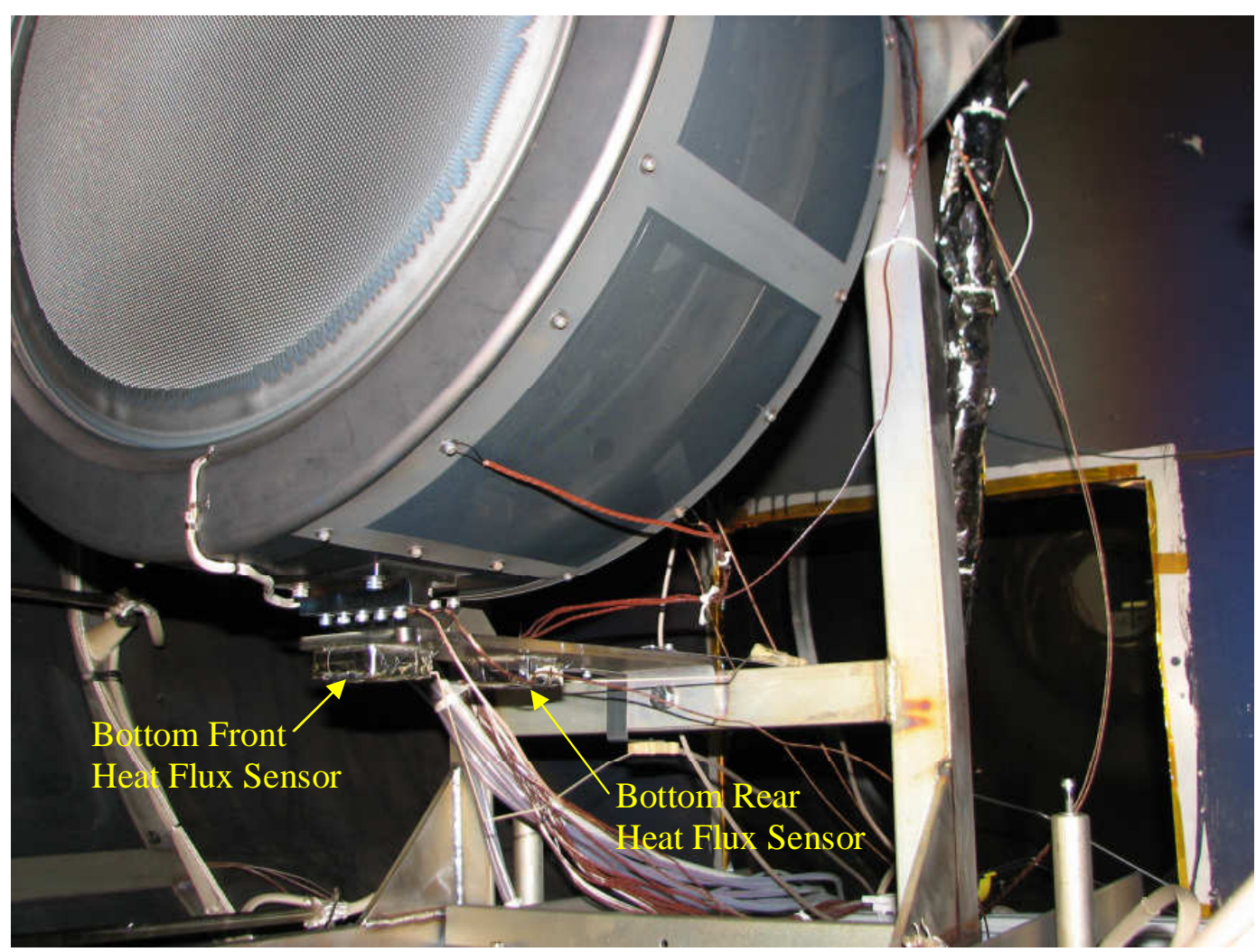

Figure 4. NEXT PM1 and Bottom Heat Flux Sensors. 


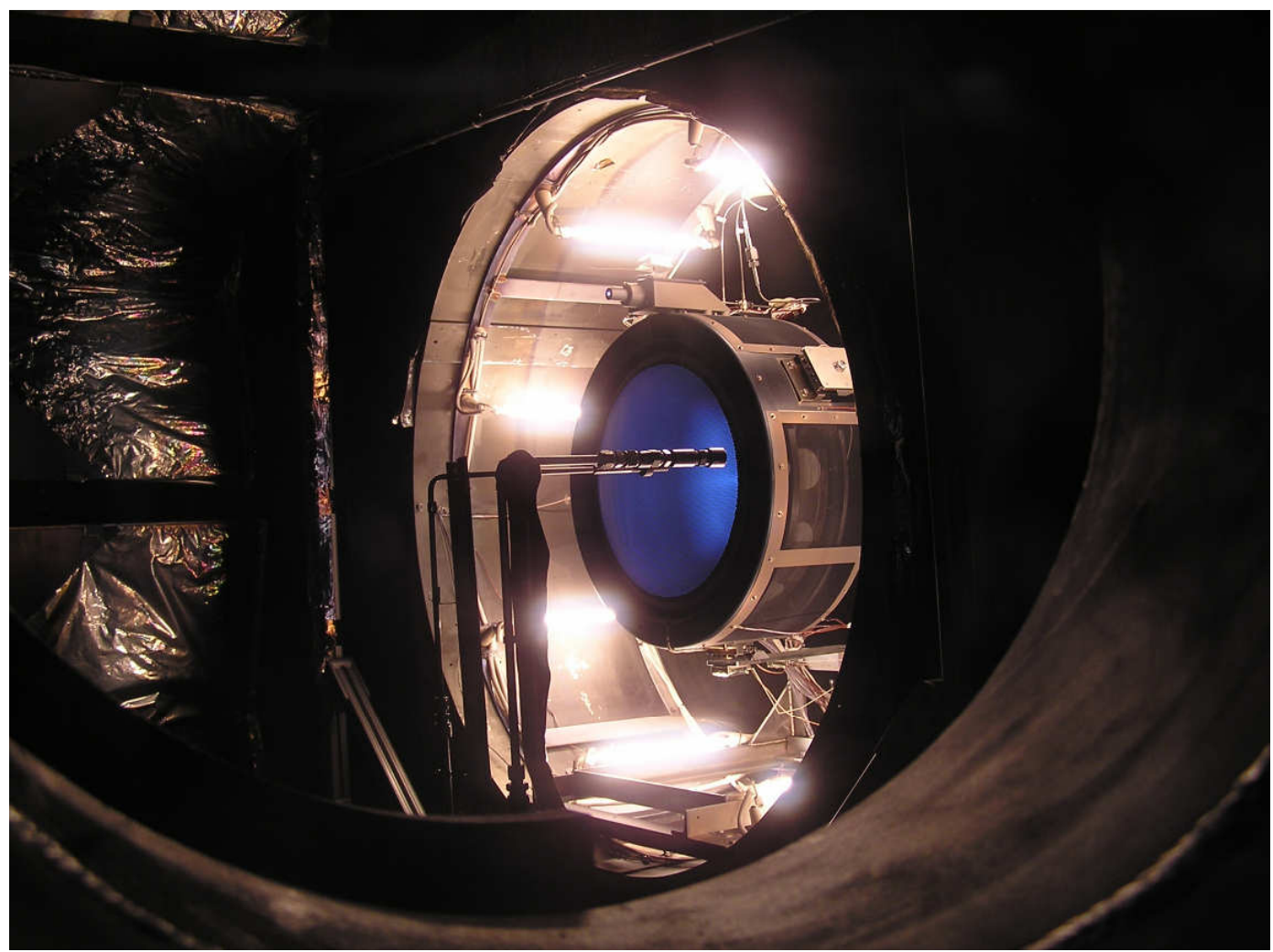

Figure 5. NEXT PM1 in Shroud with Heat Lamps Operating.

Figure 5 is a photograph taken through a side port in the vacuum chamber. Seen in the photograph is NEXT PM1 operating in the shroud with heat lamp power applied. Also visible between the window and the thruster are the two Faraday probes.

\section{Functional Testing}

A performance verification test was conducted prior to initiating the functional testing. This test was performed to verify that the thruster operated properly over its throttle range after shipping to JPL. The thruster was operated at four points; discharge only, 1.20 A $679 \mathrm{~V}, 2.00 \mathrm{~A} 1179 \mathrm{~V}$ and $3.52 \mathrm{~A} 1800 \mathrm{~V}$. The thruster operated nominally at all points.

Once verification testing was completed, pre-TDT functional testing was performed to obtain steady-state engine performance, characterize the neutralizer, measure electron backstreaming limit and perveance margin, determine double-to-single ion current ratios and characterize the beam current density profile. This functional testing was repeated subsequent to the thermal development test.

\section{A.Functional Test Data}

The pre-TDT functional testing was performed at 3 operating conditions; $1.20 \mathrm{~A} 679 \mathrm{~V}, 2.00 \mathrm{~A} 1179 \mathrm{~V}$ and $3.52 \mathrm{~A} 1800 \mathrm{~V}$. The post-TDT functional testing was conducted at these three points as well as at an additional point-3.52 A, $1179 \mathrm{~V}$. The thruster operating points are designed to maintain a constant thrust and specific impulse over the life of the thruster. Thruster degradation will manifest itself as a decrease in thruster efficiency because more power will be required to provide the demanded thrust and specific impulse. Thruster performance data from the pre-TDT and post-TDT functional testing is shown in Figures 6, 7 and 8.

The thrust from NEXT PM1 is computed from the measured beam current and voltage. Also included in the thrust computation are corrections for double ion current and beam divergence losses. The computed thrust data is shown in Figure 6 as a function of thruster power. The thruster power includes the power from the beam, discharge, accelerator, and neutralizer power supplies required to operate the thruster. 


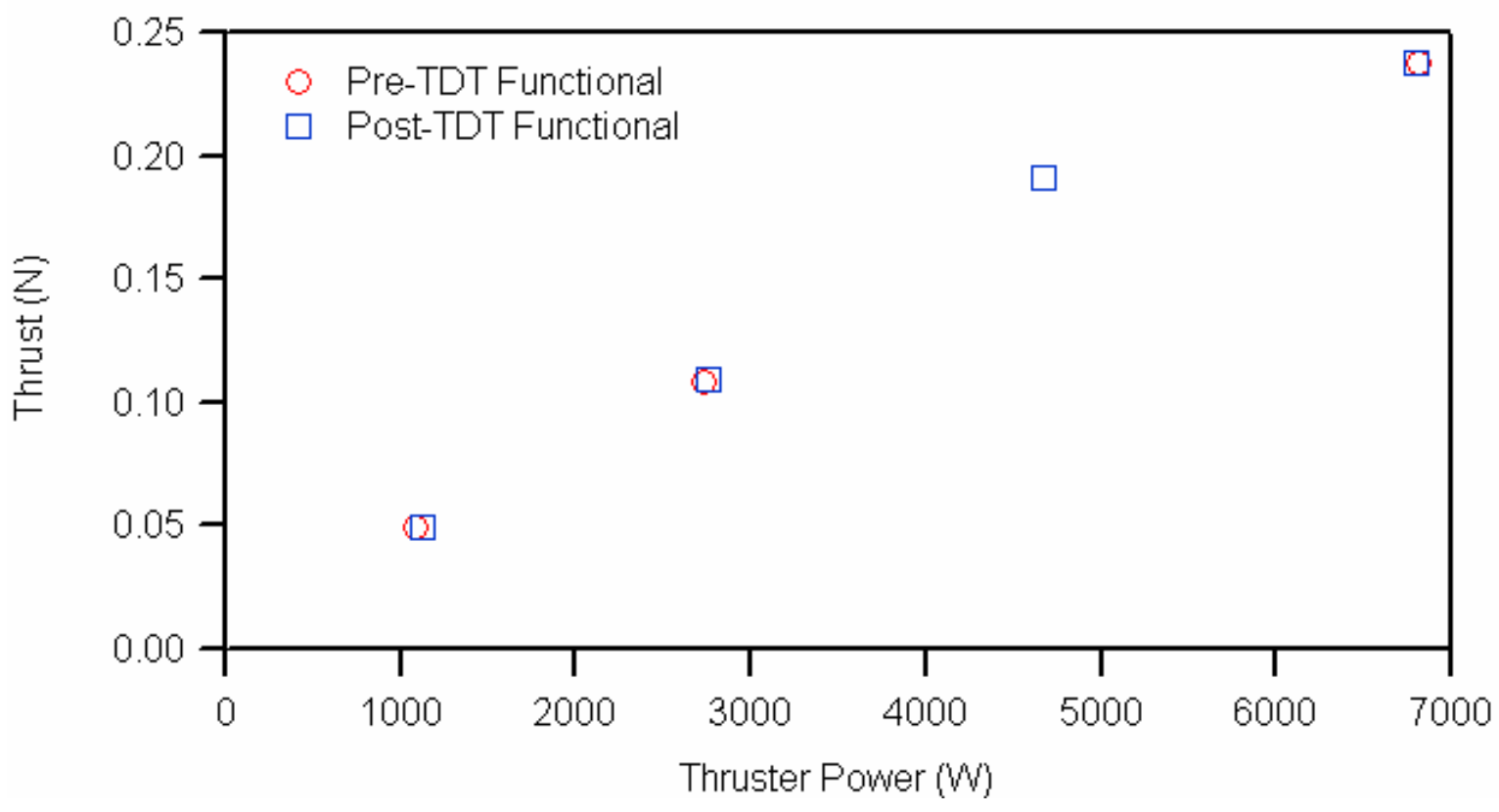

Figure 6. NEXT PM1 Thrust vs Power During Functional Testing

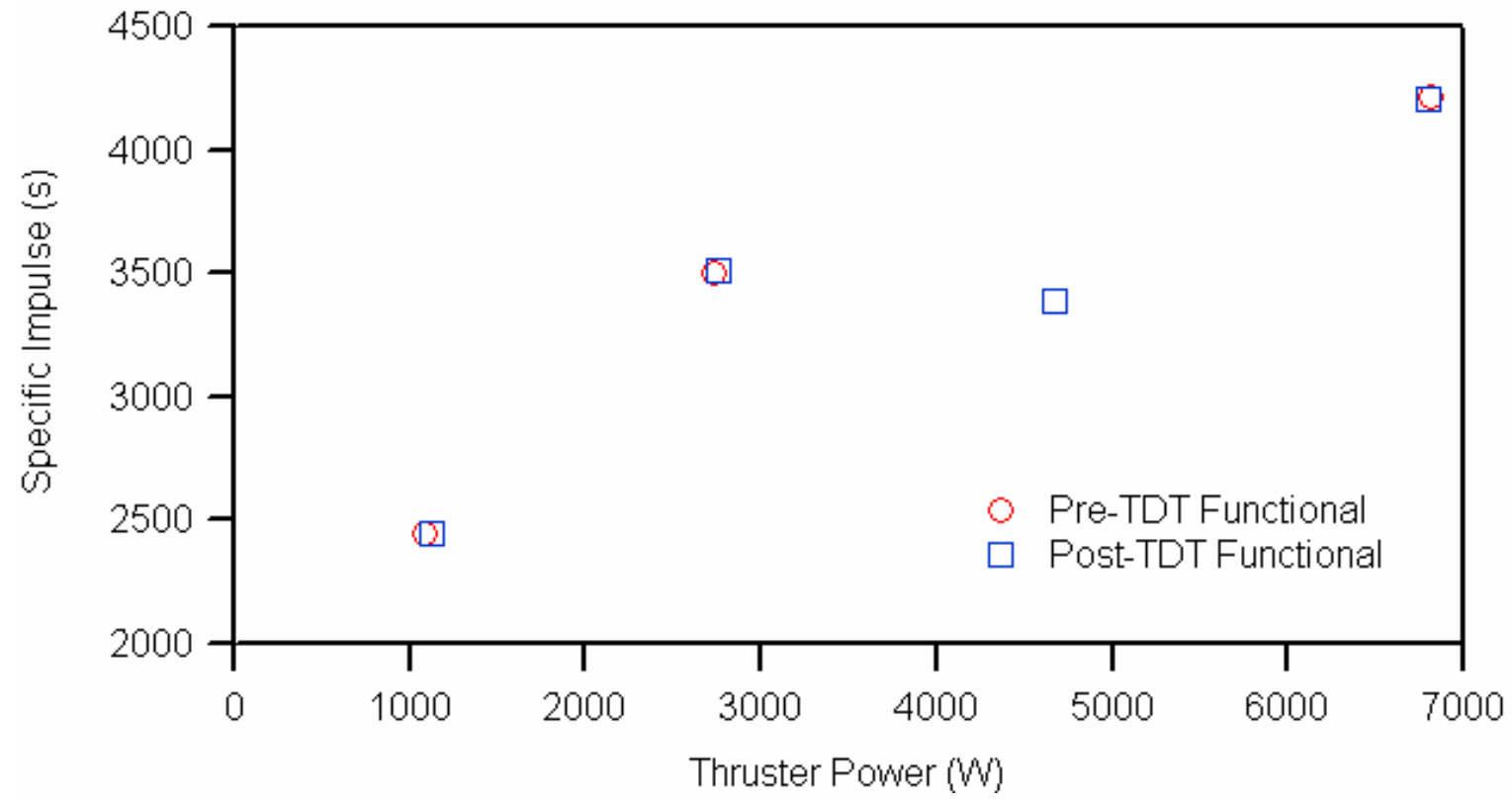

Figure 7. NEXT PM1 Specific Impulse vs Power During Functional Testing

Specific impulse is defined as the thrust divided by the propellant weight flow rate at the surface of the earth; this figure of merit gives the equivalent propellant exhaust velocity divide by the acceleration of gravity at the surface of the earth. Shown in Figure 7 are the pre-TDT and post-TDT specific impulse determined from the functional test data. The specific impulse varies as the square root of the beam voltage; for the low power case the beam voltage is $679 \mathrm{~V}$, for the high power case it is $1800 \mathrm{~V}$ and the middle two cases it is $1179 \mathrm{~V}$. The total propellant flow rate includes the propellant which is ionized and accelerated into the ion beam as well as neutral gas that leaks out of the discharge chamber and the propellant required to operate the neutralizer which is not accelerated to high velocity. Because the thruster accelerates a large fraction of the provided propellant at 
the $2.00 \mathrm{~A} 1179 \mathrm{~V}$ than at the $3.52 \mathrm{~A}, 1179 \mathrm{~V}$ case, the specific impulse is higher at the $2.00 \mathrm{~A} 1179 \mathrm{~V}$ operating point.

Thruster efficiency accounts for the effectiveness of the thruster in converting input power into thruster producing ion beam power as well as the fraction of provided propellant which is accelerated to produce thrust. NEXT PM1 efficiency as a function of thruster power during functional testing is shown in Figure 8. One of the major drivers affecting thruster efficiency is the discharge power required to produce the beam ions. During post-TDT functional testing the discharge current tended to be slightly higher and the discharge voltage was slightly lower than during pre-TDT functional testing. The slight differences tended to offset each other resulting in similar discharge power for the pre-TDT and post-TDT functional tests. As a result the thruster efficiency did not vary significantly between the two functional tests.

As seen from the data in Figures 6-8 no significant variation in thruster operating parameters was observed between the pre-TDT and post-TDT functional testing, indicating that the thruster did not suffer any adverse effects from the thermal development test. It is also noted that these data are comparable to the acceptance test data obtained at $\mathrm{GRC}^{16}$ prior to thermal development testing at JPL.

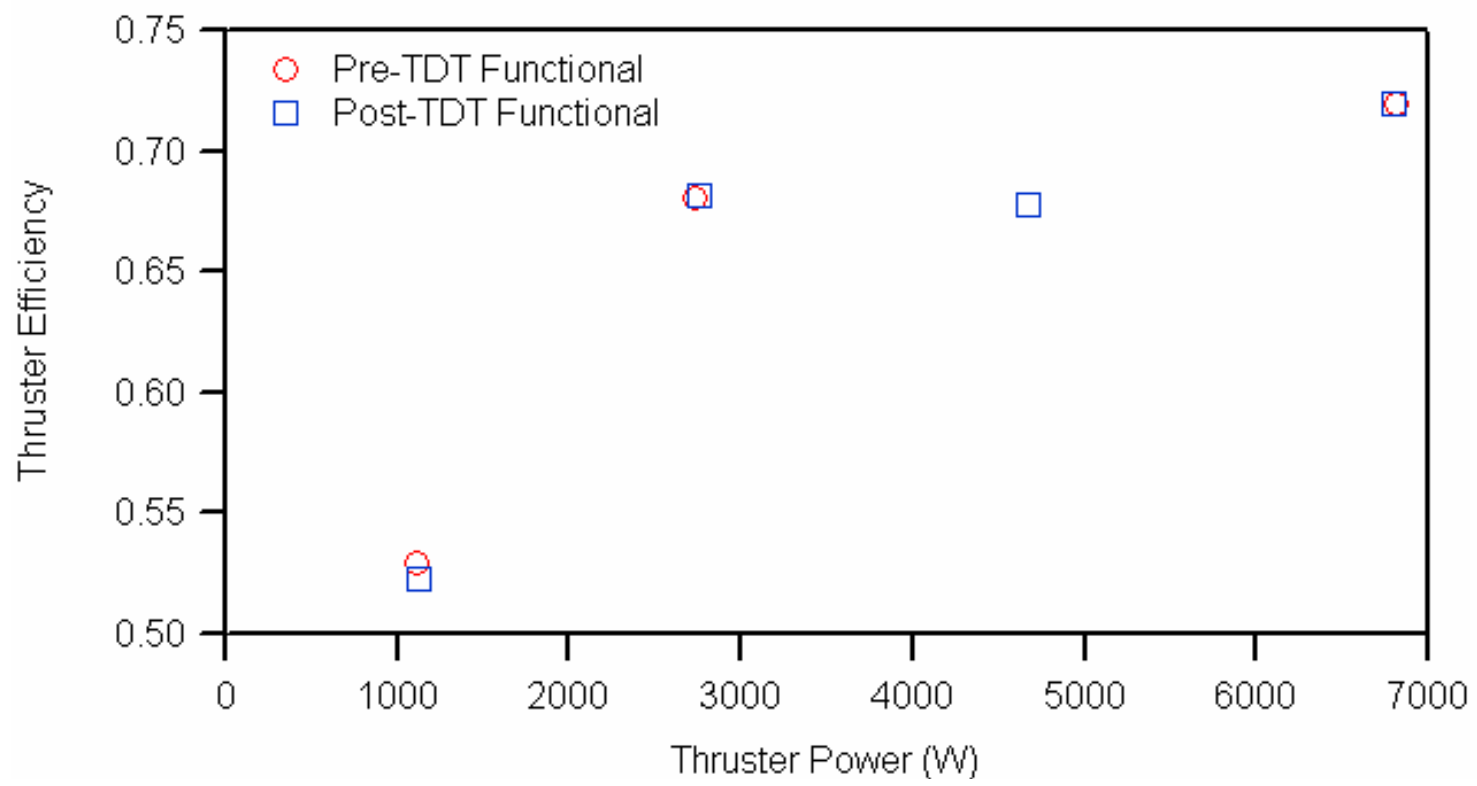

Figure 8. NEXT PM1 Efficiency vs Power During Functional Testing

\section{B.Optics and ExB Data}

During functional testing two measurements-perveance margin and electron backstreaming limit—related to the ion optics system were made. In addition ExB probe data were obtained to determine the double-to-single ion current ratio extracted from the thruster.

The perveance margin is measured by defocusing the ion beam until ions directly impinge on the accelerator grid. Defocusing is accomplished by reducing the screen grid voltage while holding the beam current constant. The perveance margin is defined as the difference between the screen grid voltage set point and screen grid voltage at which a $0.02 \mathrm{~mA}$ increase in accelerator grid current is caused by a $1 \mathrm{~V}$ decrease in screen grid potential. The perveance margin is determined from a curve fit of the accelerator grid current as a function of the screen grid voltage.

Electron backstreaming occurs when the potential at the center of accelerator grid apertures is insufficiently negative to preventing electrons from traveling upstream into the discharge chamber. Both electrons traveling upstream into the discharge chamber and positive ions traveling downstream are measured as positive current; when electron backstreaming occurs the indicated beam current increases. During the electron backstreaming tests beam control was disabled and the discharge current was maintained at a constant value. Initially the beam current decreases slightly because the electric field between the grids decreases as the accelerator grid voltage increases. However, when the accelerator grid potential increases to the point that electron backstreaming begins the indicated 
beam current begins to increase. The electron backstreaming limit is determined by raising the accelerator grid voltage until the indicated beam current increases by $1 \mathrm{~mA}$ above the lowest beam current measured during the process.

The double-to-single ion current ratio is measured using the ExB probe with the collimator viewing the center of the NEXT PM1 optics. The measured ratio is corrected for charge exchange losses ${ }^{17}$ while the beam traverses the distance between the thruster and the probe. This was done by assuming the pressure was constant throughout the vacuum chamber and integrating the loss of double and single ions, due to charge-exchange with neutrals, over the distance between the thruster and the probe.

Perveance margin, electron backstreaming limit and ExB probe data for the pre-TDT and post-TDT functional testing is tabulated in Table 2. The variation in the pre-TDT and post-TDT perveance margin and electron backstreaming limit are within typical experimental scatter. This indicates that no significant changes to the ion optics occurred during the thermal development test. The ExB data do not vary between the two functional tests. These data are also comparable to those obtained during acceptance testing at GRC.

Table 2. NEXT Functional Test Flow Perveance Margin, Electron Backstreaming Limit and ExB probe Data

\begin{tabular}{|c|c|c|c|}
\hline Functional Test Case & $\begin{array}{c}\text { Perveance } \\
\text { Margin } \\
\text { (V) }\end{array}$ & $\begin{array}{c}\text { Electron } \\
\text { Backstreaming } \\
\text { Limit } \\
\text { (V) }\end{array}$ & $\begin{array}{c}\text { Double to Single } \\
\text { Ion Current } \\
\text { Ratio* }\end{array}$ \\
\hline Pre-TDT Cases: & & -49 & \\
\hline $1.2 \mathrm{~A}, 679 \mathrm{~V}$ & 227 & -103 & 0.07 \\
\hline $2.0 \mathrm{~A}, 1179 \mathrm{~V}$ & 720 & -167 & 0.05 \\
\hline $3.52 \mathrm{~A}, 1800 \mathrm{~V}$ & 1150 & & 0.07 \\
\hline Post-TDT Cases: & & -47 & 0.07 \\
\hline $1.2 \mathrm{~A}, 679 \mathrm{~V}$ & 222 & -99 & 0.05 \\
\hline $2.0 \mathrm{~A}, 1179 \mathrm{~V}$ & 686 & -161 & 0.07 \\
\hline $3.52 \mathrm{~A}, 1800 \mathrm{~V}$ & 1156 & & \\
\hline $3.52 \mathrm{~A}, 1179 \mathrm{~V}$ & 532 & & \\
\hline
\end{tabular}

*Double to single ion current ratio measure at center of optics

\section{C.Neutralizer Characterization}

Neutralizer characterization is a diagnostic performed to determine the susceptibility of the neutralizer for transitioning from spot to plume mode. Plume mode is characterized by large voltage oscillations which can cause rapid erosion and deterioration of the neutralizer.

Neutralizer characterization is performed by decreasing the neutralizer flow rate until the neutralizer transitions from spot to plume mode. Plume mode is characterized by electrical oscillations in the neutralizer keeper circuit. Plume mode is defined as reaching or exceeding $5 \mathrm{~V}$ peak-to-peak oscillations measured between neutralizer keeper and neutralizer common. The neutralizer characterization was performed by lowering the flow rate to a minimum value or until the $5 \mathrm{~V}$ peak-to-peak oscillations occurred. During these tests the discharge was operating at $9 \mathrm{~A}$ current and the high voltage was turned off. To avoid picking up spurious noise, the peak-to-peak oscillations were measured across the neutralizer keeper power supply and not on the sense lines returning from the thruster.

During both the pre-TDT and post-TDT functional testing the neutralizer did not reach the $5 \mathrm{~V}$ peak-to-peak criteria because the minimum flow rate was reached first. During the pre-TDT characterization the minimum flow rate was $2.5 \mathrm{sccm}$ where the oscillations reached $4.2 \mathrm{~V}$ peak-to-peak. In the post-TDT functional the minimum flow rate was $2.9 \mathrm{sccm}$ where the oscillations were $3.4 \mathrm{~V}$ peak-to-peak.

The transition to plume mode occurred at $3.3 \mathrm{sccm}$ during the acceptance testing at GRC. The difference between the TDT and acceptance test results may be due to higher background pressure in the JPL facility (approximately 3.5 times higher) which may facilitate bridging the neutralizer plume with the ion beam. Another possible difference is the point in the circuit at which the oscillations were measured between the two facilities. The minor difference between the two tests is not deemed to be indicative of a neutralizer problem. 


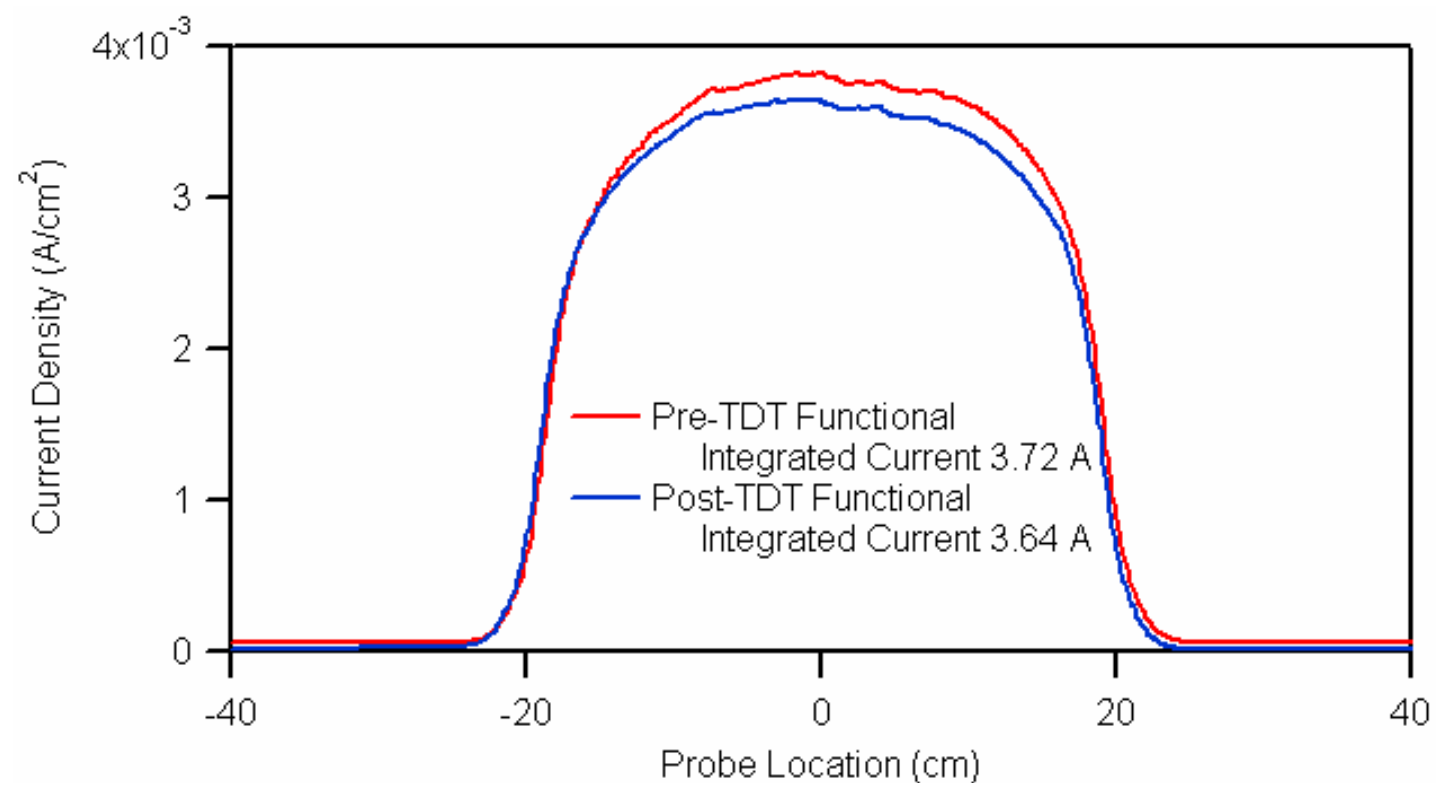

Figure 9. Comparison of Pre-TDT and Post-TDT Functional Faraday Probe Data at 1800 V, 3.52 A

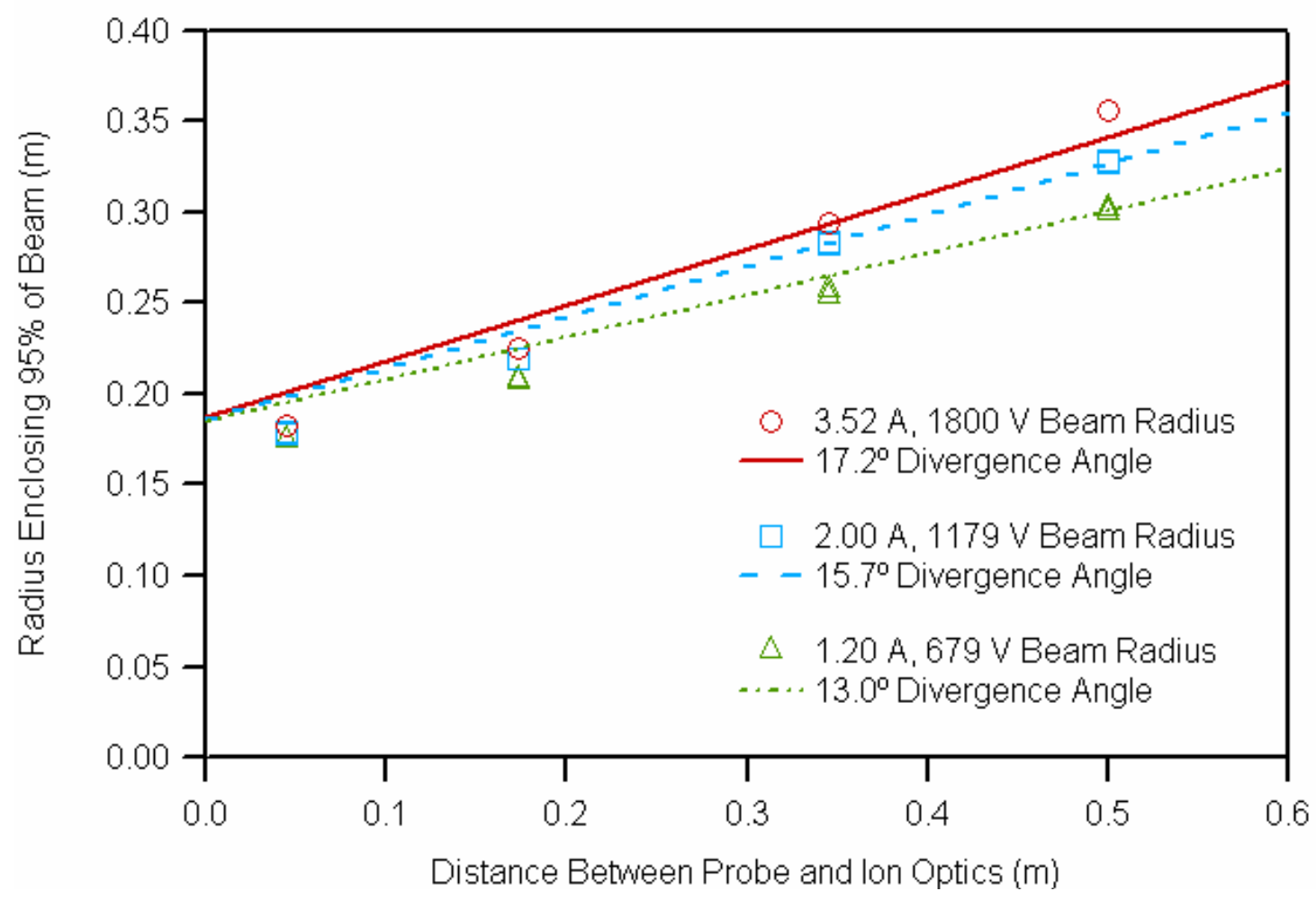

Figure 10. Beam Divergence During Post-TDT Functional Testing

\section{D.Beam Current Profiles}

Beam current density profiles were obtained with the Faraday probes. A typical plot of the Faraday probe data comparing pre-TDT and post-TDT testing is shown in Figure 9. These traces were obtained with the probes $4.5 \mathrm{~cm}$ 
downstream of the accelerator grid. The variation in the data between the two tests is comparable to the differences seen at other probe locations and thruster operating conditions. Integration of the Faraday probe traces typically yielded currents slightly higher than the beam current. The discrepancy may be due uncertainty in estimating the probe ion collection area and in with integration of the current density at large radial distances from the beam centerline.

Faraday probe sweeps were obtained at axial distances from the optics ranging from $4.5 \mathrm{~cm}$ to $0.53 \mathrm{~m}$. Beam divergence estimates were obtained from these data. The radius that contained 0.95 of the beam was determined from the integration of the beam current. Using this radius and the active grid radius of $0.18 \mathrm{~m}$ and accounting for the grid dishing the beam divergence angle was computed. Typical divergence data obtained during the post-TDT functional testing is shown in Figure 10.

\section{Thermal Testing}

Thermal testing was conducted at cold (liquid nitrogen cooling the shroud), ambient (no active external heating or cooling) and hot (heat lamps radiating to thruster and shroud) conditions. These tests encompassed the range of thermal conditions expected during the deep space design reference missions investigated under the NEXT program. During these tests the thruster was operated at each point until steady-state temperatures were reached. For this testing steady-state was defined as a rate of temperature change less than $4{ }^{\circ} \mathrm{C}$ per hour.

A specific spacecraft configuration for mounting NEXT has not been identified yet; therefore, the boundary conditions for the NEXT thermal model can only be approximated. In spaceflight the heat flux from the sun would heat one side, or the optics end, of the thruster while the remaining surfaces might radiate toward deep space or other spacecraft surfaces. The experimental set up used during testing is different from that expected in space because the heat lamps were evenly spaced around the cylindrical portion of the thruster. As a result the entire cylindrical section was heated instead of just one side.

A preliminary analysis with a sample spacecraft thermal model estimated the maximum solar heat flux to NEXT during potential missions. This estimate was based on the maximum solar flux found in a deep space design reference mission (DSDRM) analysis performed by Aerojet ${ }^{4}$. This maximum solar heat flux, $1400 \mathrm{~W} / \mathrm{m}^{2}$, occurs with the thruster operating at $0.85 \mathrm{AU}$ at a sun angle of 38 degrees. Multiplying the heat flux by the projected area of the thruster illuminated by the sun the total solar power radiated to NEXT was estimated to be $450 \mathrm{~W}$. During hot testing radiated heat loads between 650 and $1000 \mathrm{~W}$ were applied to the thruster. The $650 \mathrm{~W}$ case includes the $450 \mathrm{~W}$ flux determined from mission analysis plus $200 \mathrm{~W}$ estimated to be supplied from the spacecraft interface. The $1000 \mathrm{~W}$ test was performed to determine the external heat flux required to reach the do-not-exceed temperature limit a thruster component.

During the thermal development test data was obtained at a variety of thruster operating conditions and thermal environments as listed in Table 3. Four cases, denoted as cold cases, were run with the shroud actively cooled with LN2. Eight ambient cases were tested; in these tests there was no active control of the thermal environment. Four hot cases were run at two heat flux coupon set points. The $100{ }^{\circ} \mathrm{C}$ set point corresponds to the $650 \mathrm{~W}$ heat flux case and the $145^{\circ} \mathrm{C}$ set point is the $1000 \mathrm{~W}$ heat flux case. The $3.52 \mathrm{~A}, 1179 \mathrm{~V}$ and $3.52 \mathrm{~A}, 1800 \mathrm{~V}$ operating points were tested under cold, ambient and hot conditions. Several other operating points were tested at ambient conditions.

Table 3. NEXT PM1 Throttle Table. Cold Cases:

Neutralizer Heater (7.2 A, 8.7 V)

Cathode Heater (7.2 A, 13.7 V)

$3.52 \mathrm{~A}, 1179 \mathrm{~V}$ (TDT 7)

$3.52 \mathrm{~A}, 1800 \mathrm{~V}$ (TDT 8)

Ambient Cases:

Discharge Only

$1.00 \mathrm{~A}, 275 \mathrm{~V}$ (TDT 1)

$1.20 \mathrm{~A}, 679 \mathrm{~V}$ (TDT 2)

$1.20 \mathrm{~A}, 1179 \mathrm{~V}$ (TDT 3)

$1.20 \mathrm{~A}, 1800 \mathrm{~V}$ (TDT 4)

$2.00 \mathrm{~A}, 1179 \mathrm{~V}$ (TDT 5)

$3.52 \mathrm{~A}, 1179 \mathrm{~V}$ (TDT 7)

$3.52 \mathrm{~A}, 1800 \mathrm{~V}$ (TDT 8)

Hot Cases:

Thruster Off $\quad\left(100{ }^{\circ} \mathrm{C}\right.$ Set Point $)$

$3.52 \mathrm{~A}, 1179 \mathrm{~V}\left(100^{\circ} \mathrm{C}\right.$ Set Point $)$

$3.52 \mathrm{~A}, 1179 \mathrm{~V}\left(145^{\circ} \mathrm{C}\right.$ Set Point $)$

$3.52 \mathrm{~A}, 1800 \mathrm{~V}\left(100^{\circ} \mathrm{C}\right.$ Set Point $)$

\section{A.Heat Flux Estimation}

The radiated heat flux to the thruster is estimated by using the calibration and the temperature of the heat flux coupons at steady-state thermal conditions. The area of the cylindrical portion of the thruster is $0.33 \mathrm{~m}^{2}$, the area of the conical section is $0.23 \mathrm{~m}^{2}$, and the area of the optics and front mask is $0.21 \mathrm{~m}^{2}$. At steady-state the coupon and shroud temperatures are comparable in the region with the heat lamps which surround the cylindrical portion of the thruster, suggesting that the shroud temperature could be used along with the heat flux sensor calibration to estimate the heat flux to the thruster. The temperature at the back of the shroud, which interacts with the conical section of 
the thruster, tend to be lower than the shroud temperatures surrounding the cylindrical section of the thruster; therefore, the heat flux to the thruster is lower in the conical region than in the cylindrical portion of the thruster. The temperature of the chamber interacting with the optics and front mask varies depending on where the ion beam is depositing power. For the hot cases with the thruster operating the chamber surface temperatures ranged from $20^{\circ} \mathrm{C}$ on the side walls to $100{ }^{\circ} \mathrm{C}$ at the center of the downstream chamber wall. To obtain a conservative estimate of the heat flux to the thruster the radiation to the optics and front mask was assumed to be black body at a temperature of $25^{\circ} \mathrm{C}$.

The heat flux to the thruster at three operating conditions is estimated. The cases are at ambient with the thruster operating at full power, and two hot cases with the thruster operating at beam conditions of $3.52 \mathrm{~A}, 1179 \mathrm{~V}$ and the heat lamp set point at $100{ }^{\circ} \mathrm{C}$ and $145^{\circ} \mathrm{C}$.

At ambient full power operation $(3.52 \mathrm{~A}, 1800 \mathrm{~V})$ the coupon temperatures were 61 and $63{ }^{\circ} \mathrm{C}$, the back of the shroud was $\sim 56^{\circ} \mathrm{C}$, and the vacuum chamber temperature was $25^{\circ} \mathrm{C}$. Using these temperatures and the coupon calibration multiplier, the estimated total heat flux to the thruster operating at full power at ambient conditions is $450 \mathrm{~W}$.

For the thruster operating at $3.52 \mathrm{~A}, 1179 \mathrm{~V}$ with the heat flux coupons at $100{ }^{\circ} \mathrm{C}$, the back of the shroud was at about $90{ }^{\circ} \mathrm{C}$ and again using a vacuum chamber temperature of $25^{\circ} \mathrm{C}$, the estimated heat flux to the thruster was $650 \mathrm{~W}$.

The highest heat flux case during the thermal development test also was conducted at beam conditions of $3.52 \mathrm{~A}$, $1179 \mathrm{~V}$. For this case the coupon temperatures were $144{ }^{\circ} \mathrm{C}$, the back of the shroud was at $134{ }^{\circ} \mathrm{C}$ and once again the vacuum chamber temperature of $25^{\circ} \mathrm{C}$ is used. For this case the total heat flux to the thruster is estimated to be $1000 \mathrm{~W}$.

\section{B.Temperature Data}

A significant contributor to the thermal environment influencing the thruster is shroud surrounding the side and back of the thruster. Shroud temperature data for all 14 shroud thermocouples as a function of rear heat flux sensor temperature, at steady-state, is shown in Figure 11. The two coldest cases correspond to the neutralizer and cathode heater cold cases. During these tests the shroud door was closed resulting in the lowest shroud temperatures. Some radiation from the thruster could reflect from the door and shroud surfaces resulting in coupon temperatures higher than those of the shroud. The remaining two cold cases (below $0{ }^{\circ} \mathrm{C}$ ) were with the door open and the thruster operating; the heat flux coupon temperatures were higher because they could partially view the warmer environment outside the shroud. The data between 0 and $80^{\circ} \mathrm{C}$ are ambient cases where there was no active heating or cooling of the shroud. The thruster radiates to the shroud resulting in high shroud temperatures at higher thruster power operating conditions. The data at $\sim 100^{\circ} \mathrm{C}$ are the $650 \mathrm{~W}$ heat flux cases and the data near $150^{\circ} \mathrm{C}$ are the $1000 \mathrm{~W}$ heat flux case.

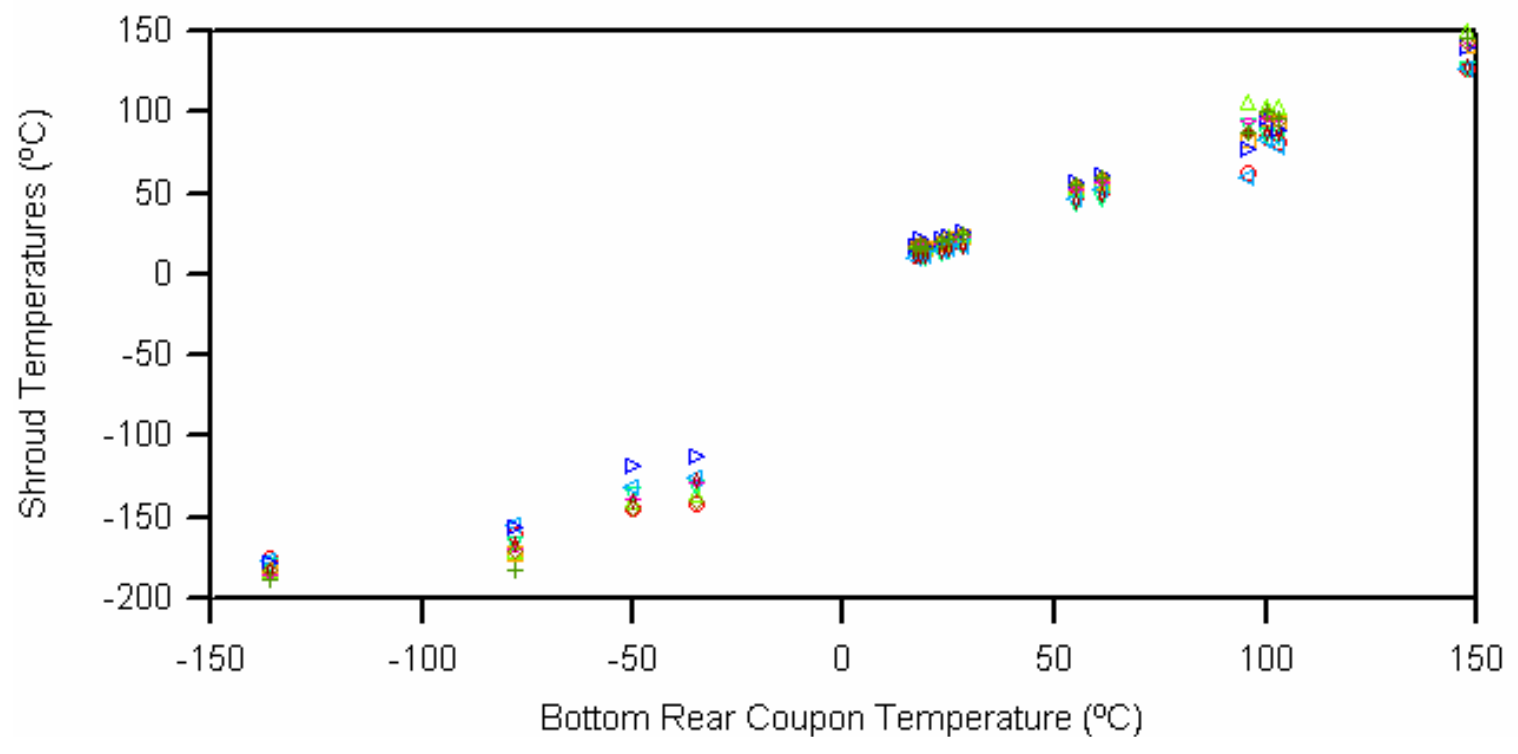

Figure 11. Shroud Temperatures vs Bottom Rear Heat Flux Sensor Temperature at Steady-State. 


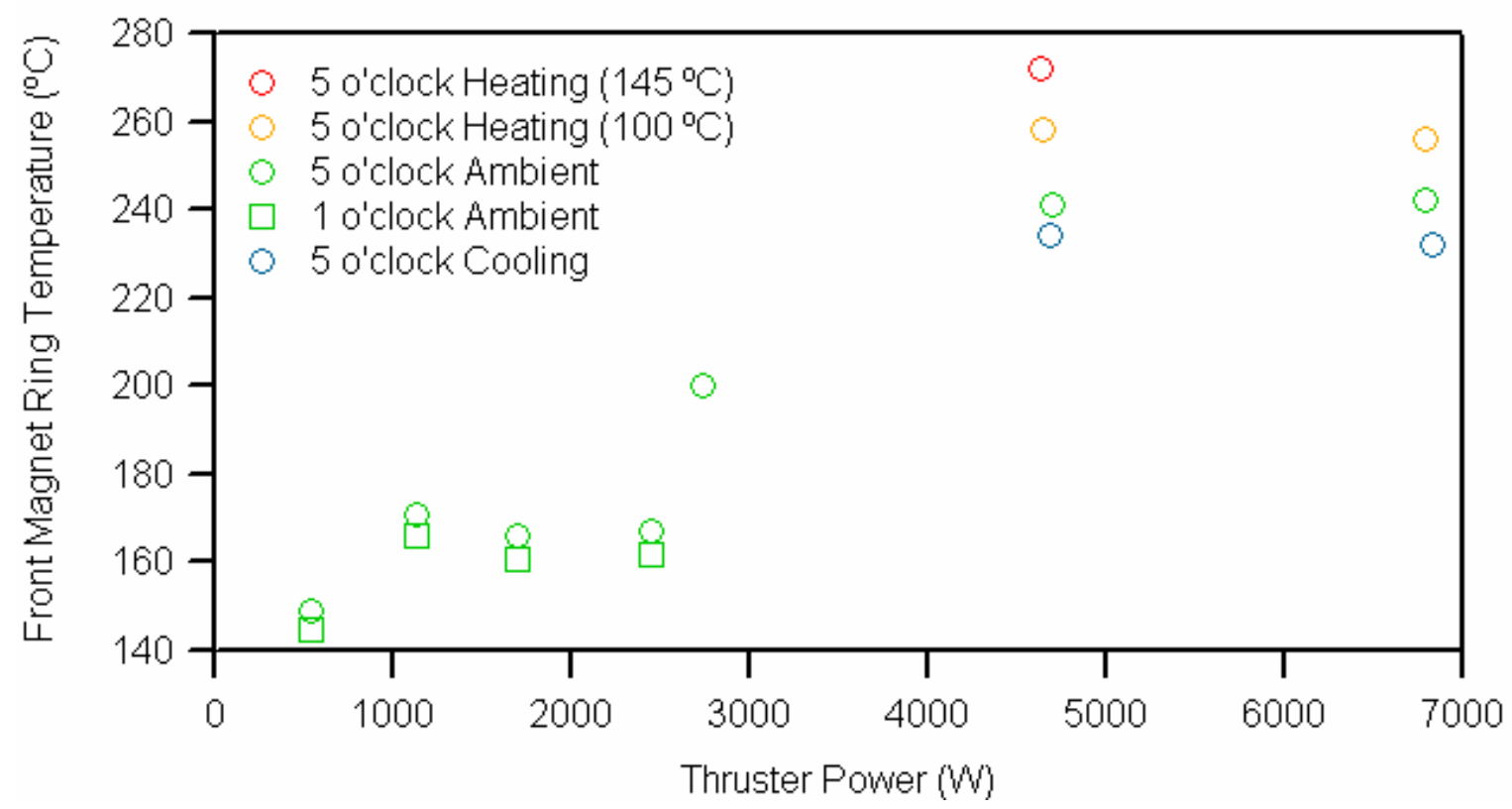

Figure 12a. Steady-State Front Magnet Ring Temperature During Thermal Development Testing

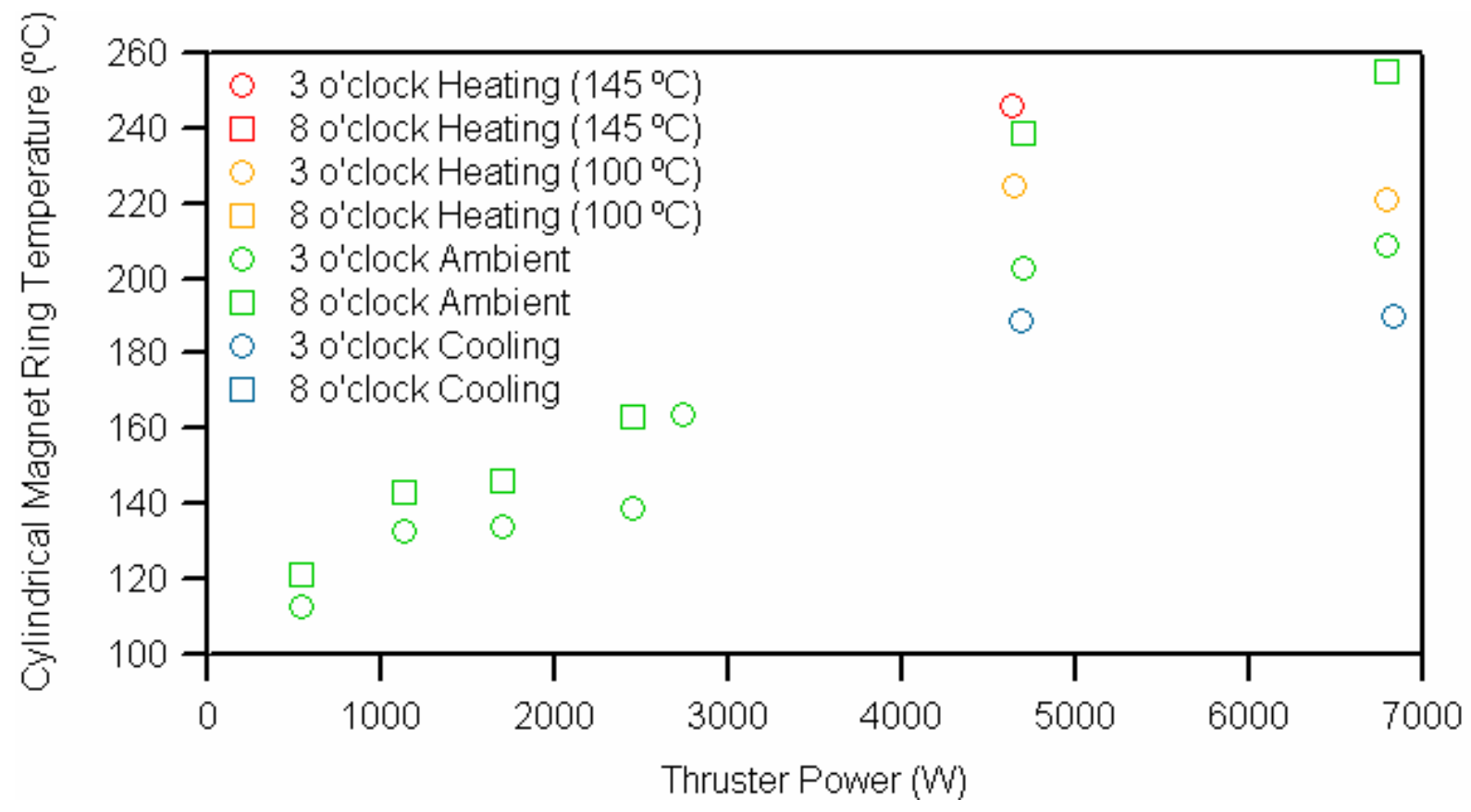

Figure 12b. Steady-State Cylindrical Magnet Ring Temperatures During Thermal Development Testing

It is desirable to determine the thermal margin for the magnets used in the thruster because they can degauss if they are overheated. The magnets used in the NEXT PM1 ion thruster are rated for operation at temperatures below $360{ }^{\circ} \mathrm{C}$ where they should not degrade.

The NEXT PM1 thruster magnet temperature data obtained during the thermal development test is shown in Figures 12a, 12b, 12c, and 12d. The maximum steady-state magnet temperature measure during thermal testing was $272{ }^{\circ} \mathrm{C}$ on the front magnet ring during the maximum heat flux testing; this gives a temperature margin of $88^{\circ} \mathrm{C}$ for the magnets. The electric discharge required to produce ions in the discharge chamber is the dominant contributor to 


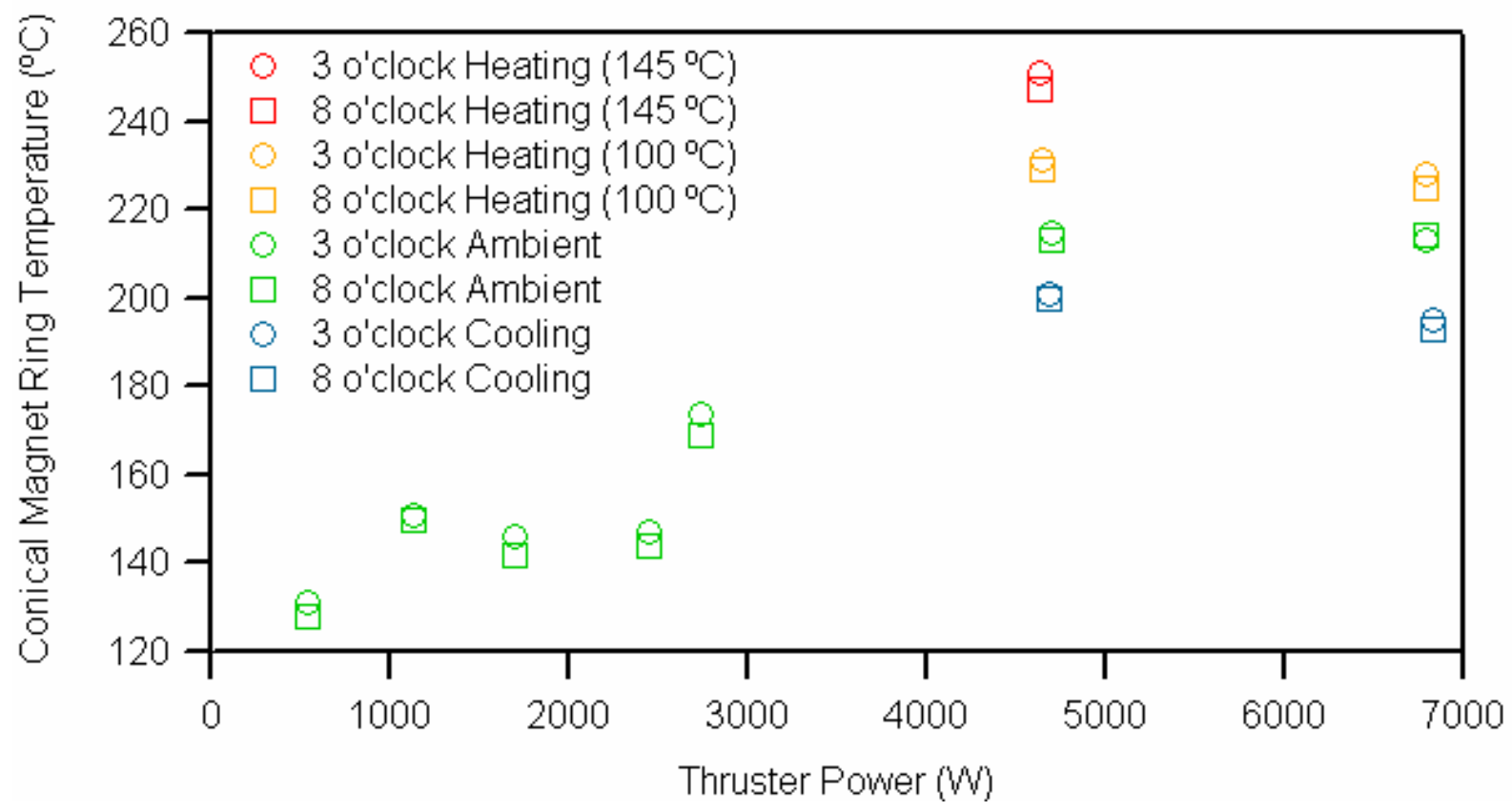

Figure 12c. Steady-State Conical Magnet Ring Temperatures During Thermal Development Testing

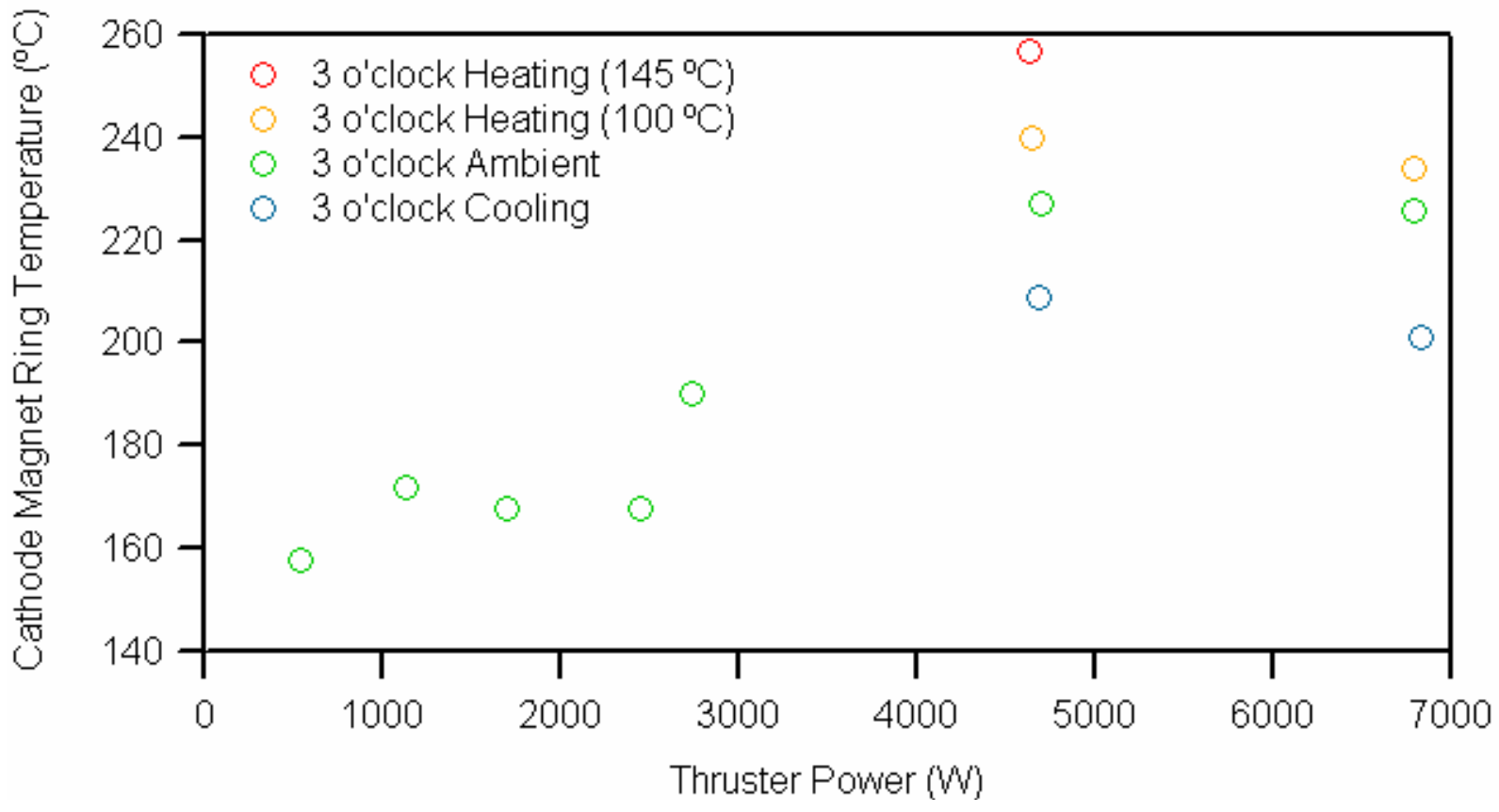

Figure 12d. Steady-State Cathode Magnet Temperatures During Thermal Development Testing

magnet heating. The discharge power increases with increasing beam current and decreases slightly as the beam voltage increases. The magnet temperatures in the ambient cases at thruster powers below $3000 \mathrm{~W}$ are lower than the magnet temperatures at the higher power levels even with active cooling of the shroud. As expected the data at the higher thruster power levels show that the magnet temperatures increase as the external heat flux to the thruster increases. 
The cylindrical magnet thermocouple at 8 o'clock failed during hot testing. During ambient testing the temperature data for this magnet is seen to be higher than the second cylindrical magnet thermocouple located at 3 o'clock. It is thought that electron backstreaming through the plasma screen above the conical magnet ring resulted in excess heating in the vicinity of the 8 o'clock thermocouple. During hot testing at $3.52 \mathrm{~A}, 1800 \mathrm{~V}$ the thermocouple insulation failed resulting in arcing to the plasma screen. Testing was interrupted to remove this thermocouple and then resumed without a thermocouple in this location.

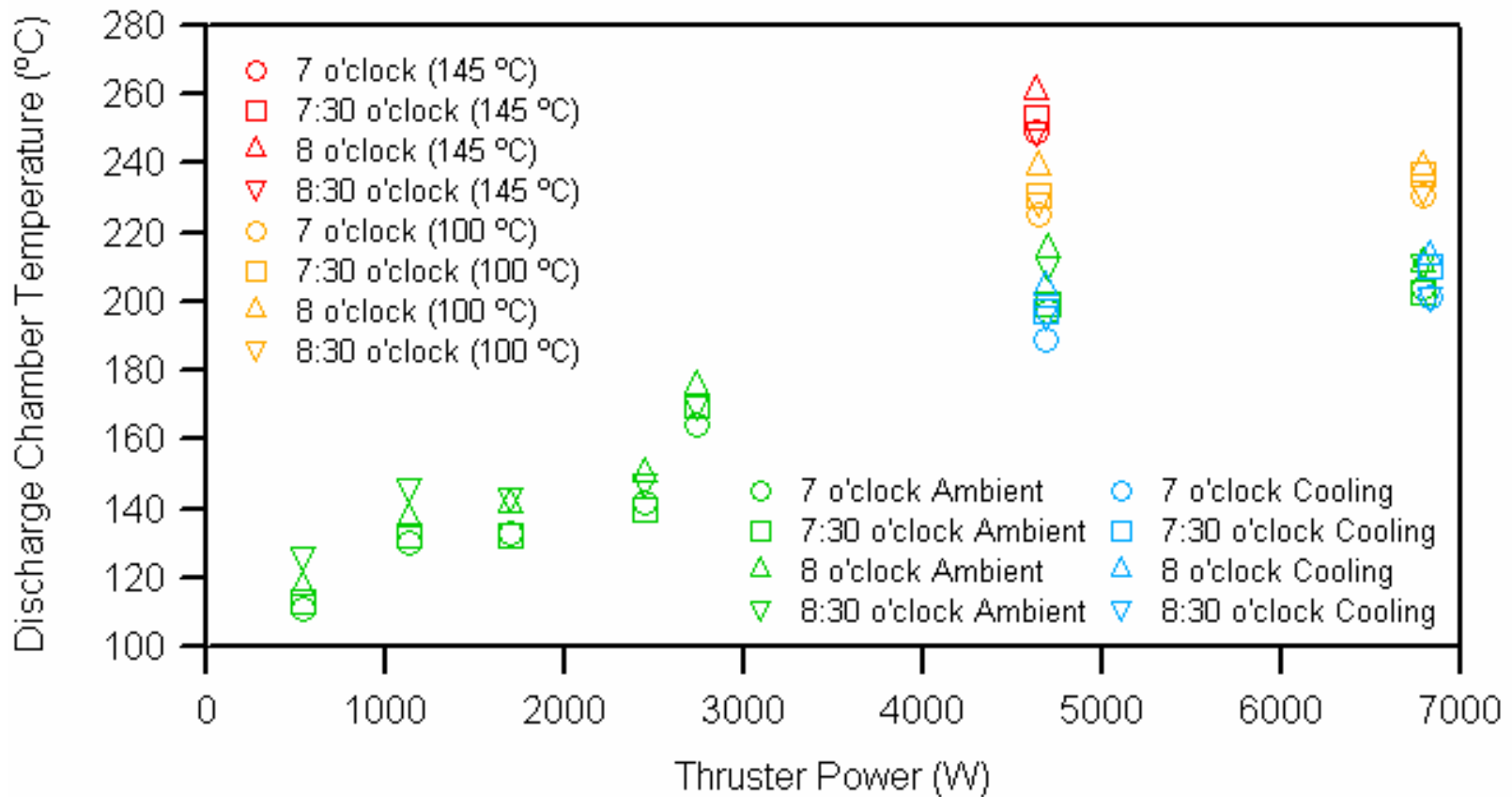

Figure 13. Steady-State Discharge Chamber Temperatures During Thermal Development Testing

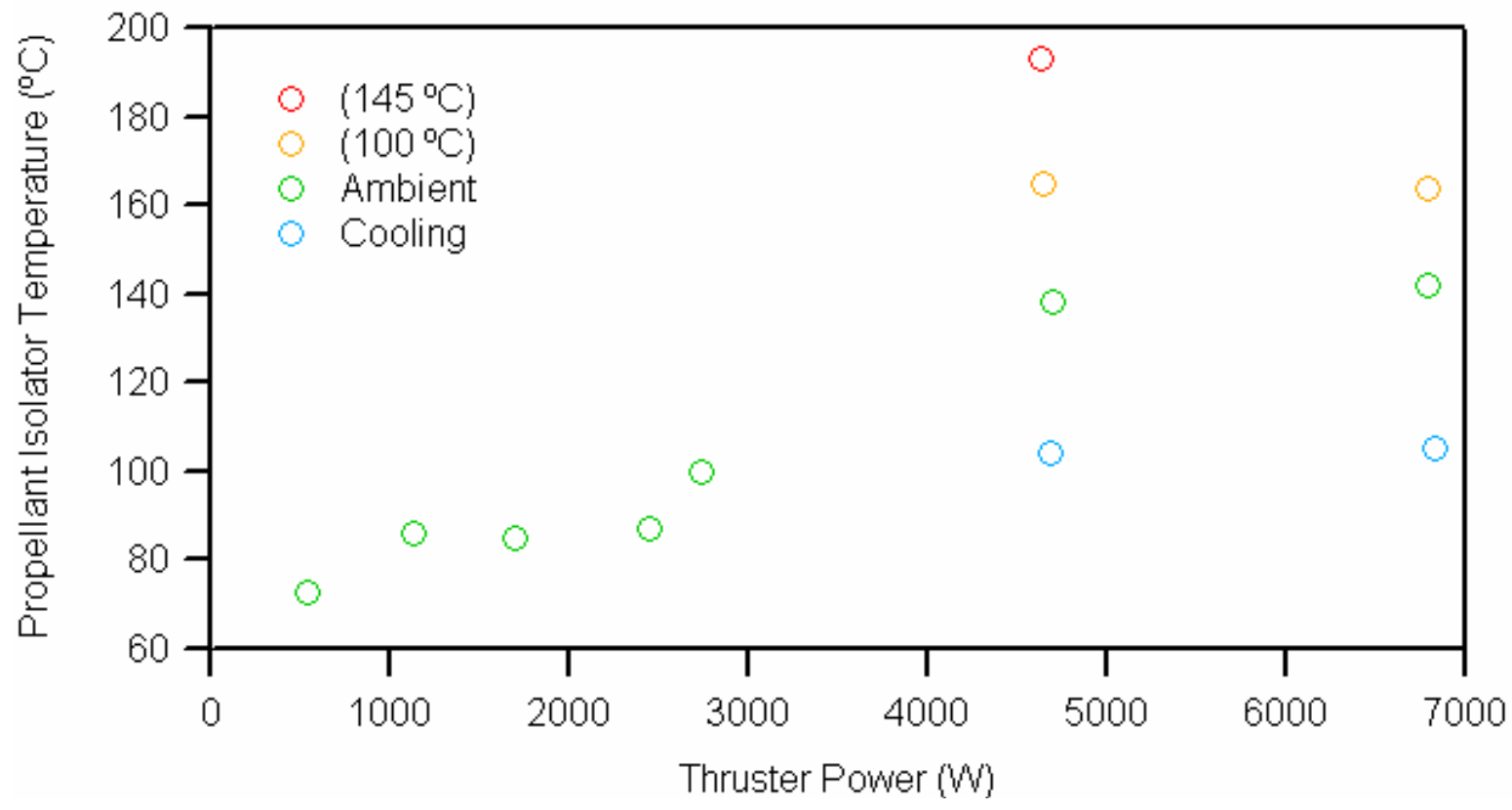

Figure 14. Steady-State Propellant Isolator Temperatures During Thermal Development Testing 
Electrons in the discharge chamber tend to be collected at the magnetic cusps formed by the magnet rings. Therefore it is expected that most of the thermal power deposited in the anode will occur at the magnets; this could result in temperature gradients in the discharge chamber. To aid in determining temperature variations due to localized heating discharge chamber thermocouples were mounted between the front and cylindrical magnets. The discharge chamber thermocouple data is shown in Figure 13; the discharge chamber thermocouples measure slightly lower temperatures than the front mask but are comparable to the cylindrical magnet temperatures. The propellant isolators are designed to allow propellant to flow from the reference potential supply to the high voltage thruster without arcing. The NEXT PM propellant isolators are rated for steady-state operation at temperatures up to $265^{\circ} \mathrm{C}$.

The propellant isolator temperature as a function of thruster power and external thermal environment is shown in Figure 14. As seen from the data the isolator had a $72{ }^{\circ} \mathrm{C}$ margin at the maximum heat flux operating condition.

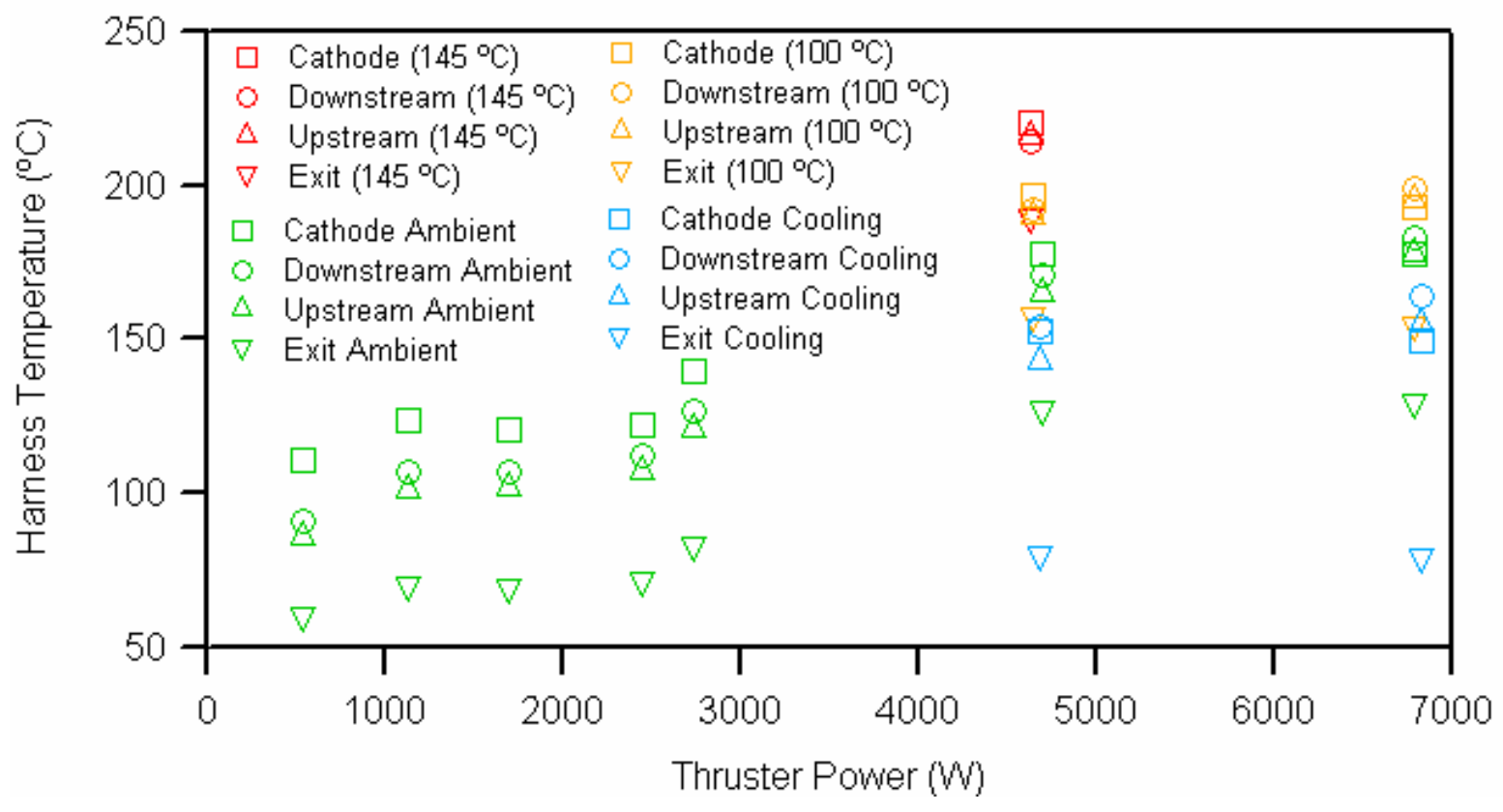

\section{Figure 15. Steady-State Wire Harness Temperatures During Thermal Development Testing}

Wire harness temperatures are shown in Figure 15. The wire harnesses located between the discharge chamber and the plasma screen are rated for operation at temperatures up to $260^{\circ} \mathrm{C}$. These thermocouples are labeled cathode, downstream and upstream in Figure 15. The jacket material used at the wire harness exit-where it penetrates the plasma screen-is rated for steady-state operation at $150{ }^{\circ} \mathrm{C}$. It was determined that operation at temperatures up to $200{ }^{\circ} \mathrm{C}$ would not damage the harness so this higher limit was imposed for testing. As expected the exit temperature is the lowest while the harness thermocouple located near the cathode is the hottest. The wire harness exit temperature reached $189^{\circ} \mathrm{C}$ during the highest heat flux testing without causing observable damage. The highest temperature for the wire harnesses under the plasma screen was $220^{\circ} \mathrm{C}$ giving a $40{ }^{\circ} \mathrm{C}$ margin.

The steady-state ion optics assembly temperatures, shown in Figure 16, follow the same trend as the magnet temperatures. The optics thermocouples are located at grid supports at the periphery of the grids. The screen grid which is in direct contact with the discharge chamber plasma is the hottest and is comparable to the magnet temperatures. The stiffening ring attaches to the discharge chamber and supports the grids temperature falls between the screen and accelerator grid which is further downstream and has the lowest temperature.

Gimbal pad temperatures are of interest because they were a candidate and were subsequently chosen as the reference temperature location for the thruster. As seen from the data in Figure 17, the gimbal pad temperatures are lower but follow the same trend as the other thruster components.

In addition to the gimbal pads the front mask was also considered as a possible reference temperature location. Front mask temperature data is shown in Figure 18. It is interesting to note the thermocouple located at the 12 o'clock position is hotter than the other thermocouples. The neutralizer is also located at 12 o'clock and radiative heating and heating from the neutralizer plasma contribute to the observed higher temperature. Front mask temperatures were used as the reference temperature location on DS1; however, due to uncertainties in the optical properties it is difficult to correlate the front mask temperature to other component temperatures. 


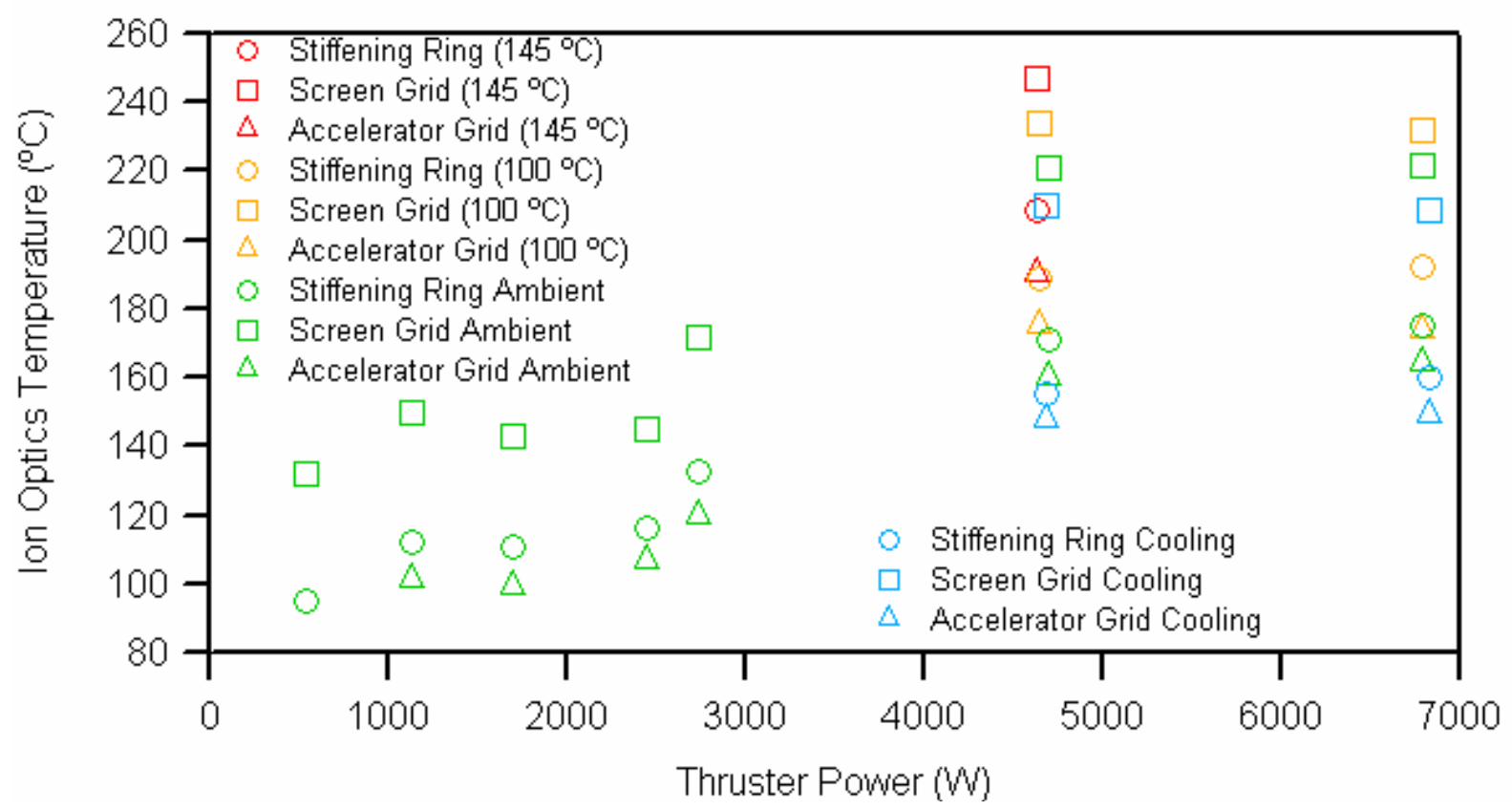

Figure 16. Steady-State Ion Optics Temperatures During Thermal Development Testing

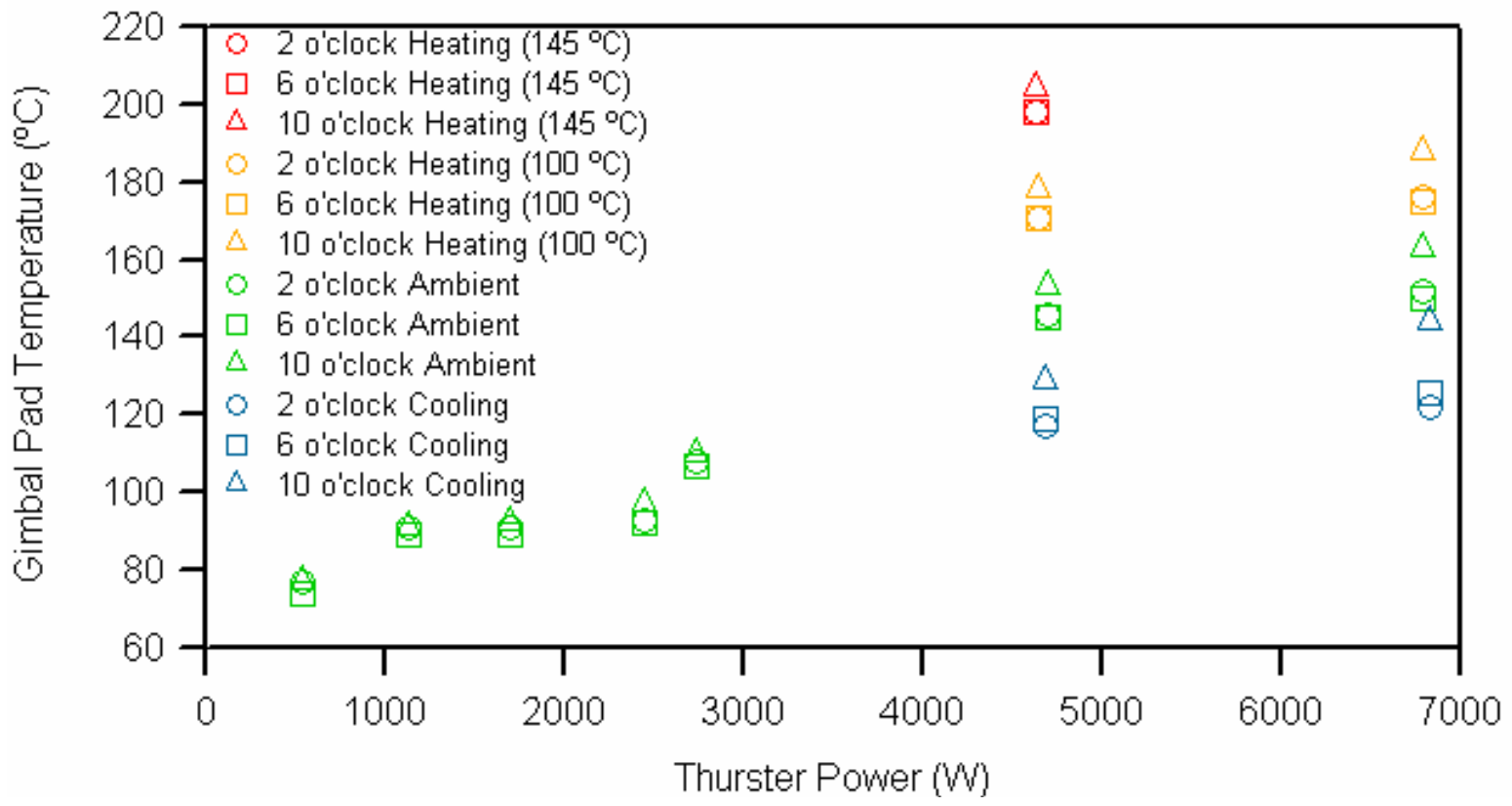

\section{Figure 17. Steady-State Gimbal Temperatures Thermal Development Testing}

The neutralizer keeper and discharge cathode tube temperatures are shown in Figure 19. Both the neutralizer and cathode active emission areas must be at thermionic temperatures for the thruster to operate. Although the thermocouples were not placed in the active emission area, they are relatively close and are at the highest temperature locations measured during thermal development testing. Because electron emission is required to operate the thruster the temperature of the cathodes does not vary greatly with the external heat load as evidenced by the data in Figure 19.

NEXT PM1 thruster performance data obtained over the environment range tested during the thermal development test is shown in Figures 20, 21 and 22. The thrust produced by the PM1 thruster is shown as a function 


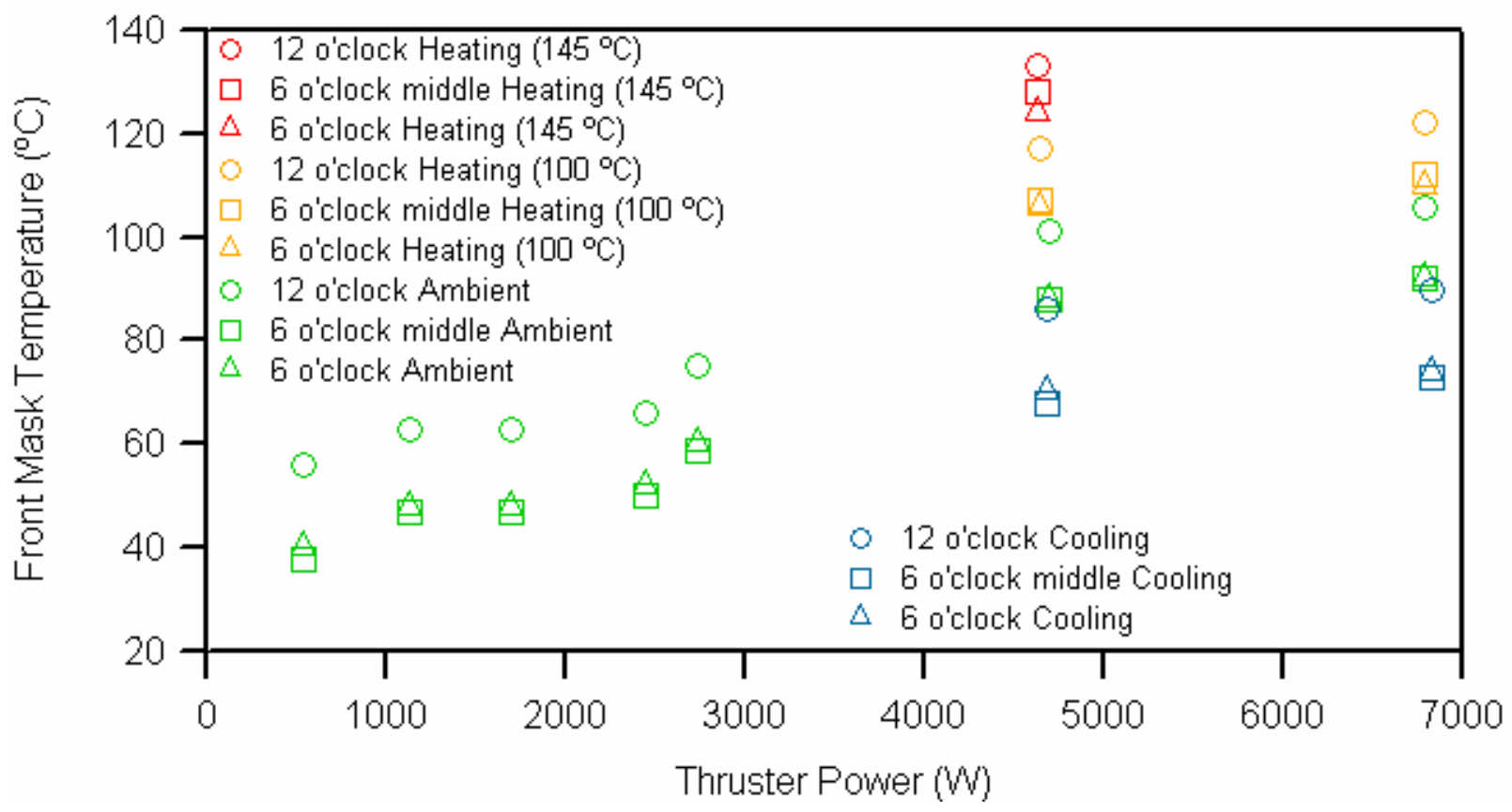

Figure 18. Steady-State Front Mask Temperatures During Thermal Development Testing

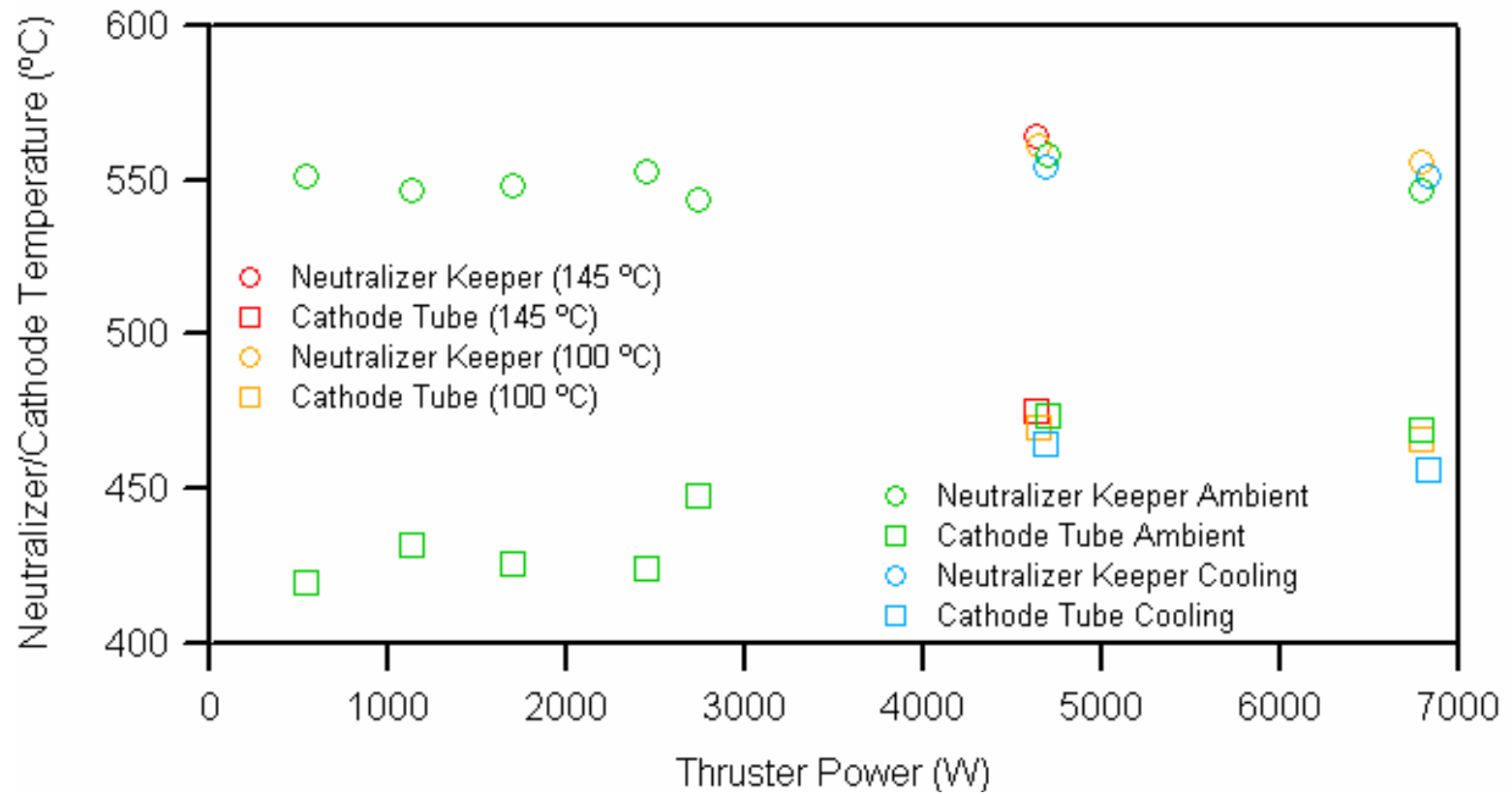

Figure 19. Steady-State Neutralizer/Cathode Temperatures During Thermal Development Testing 


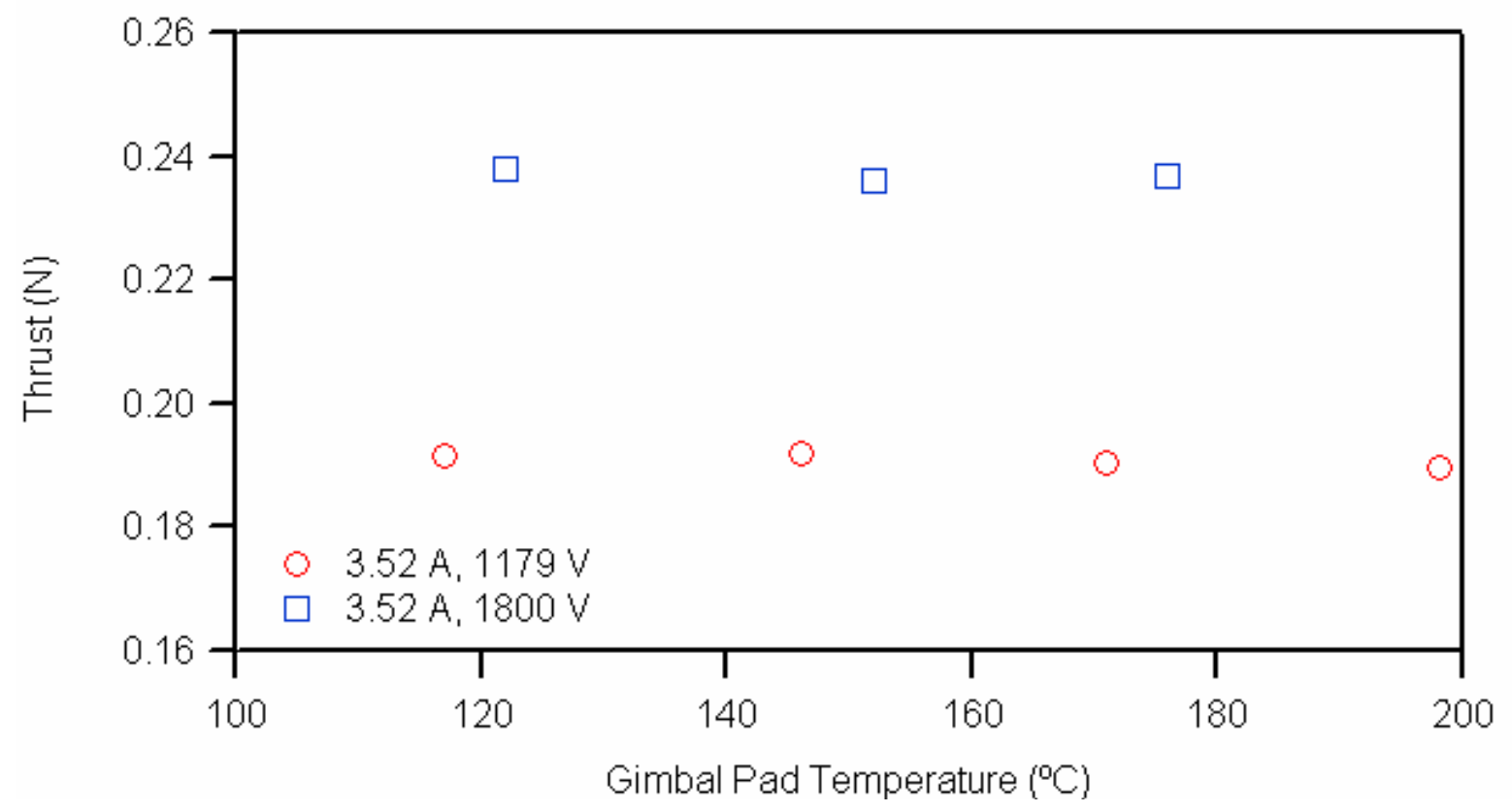

Figure 20. NEXT PM1 Thrust Over the Thermal Range

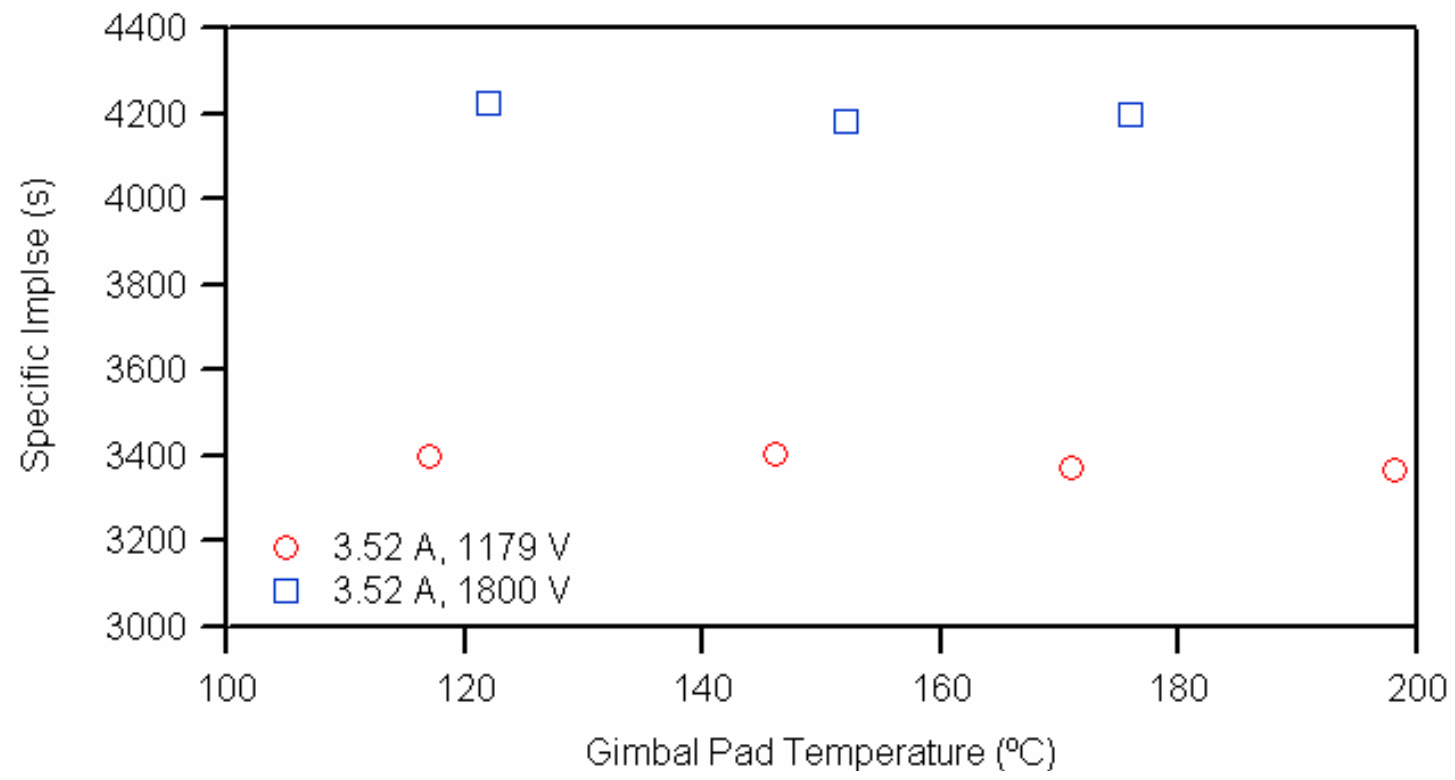

Figure 21. NEXT PM1 Specific Impulse Over the Thermal Range 


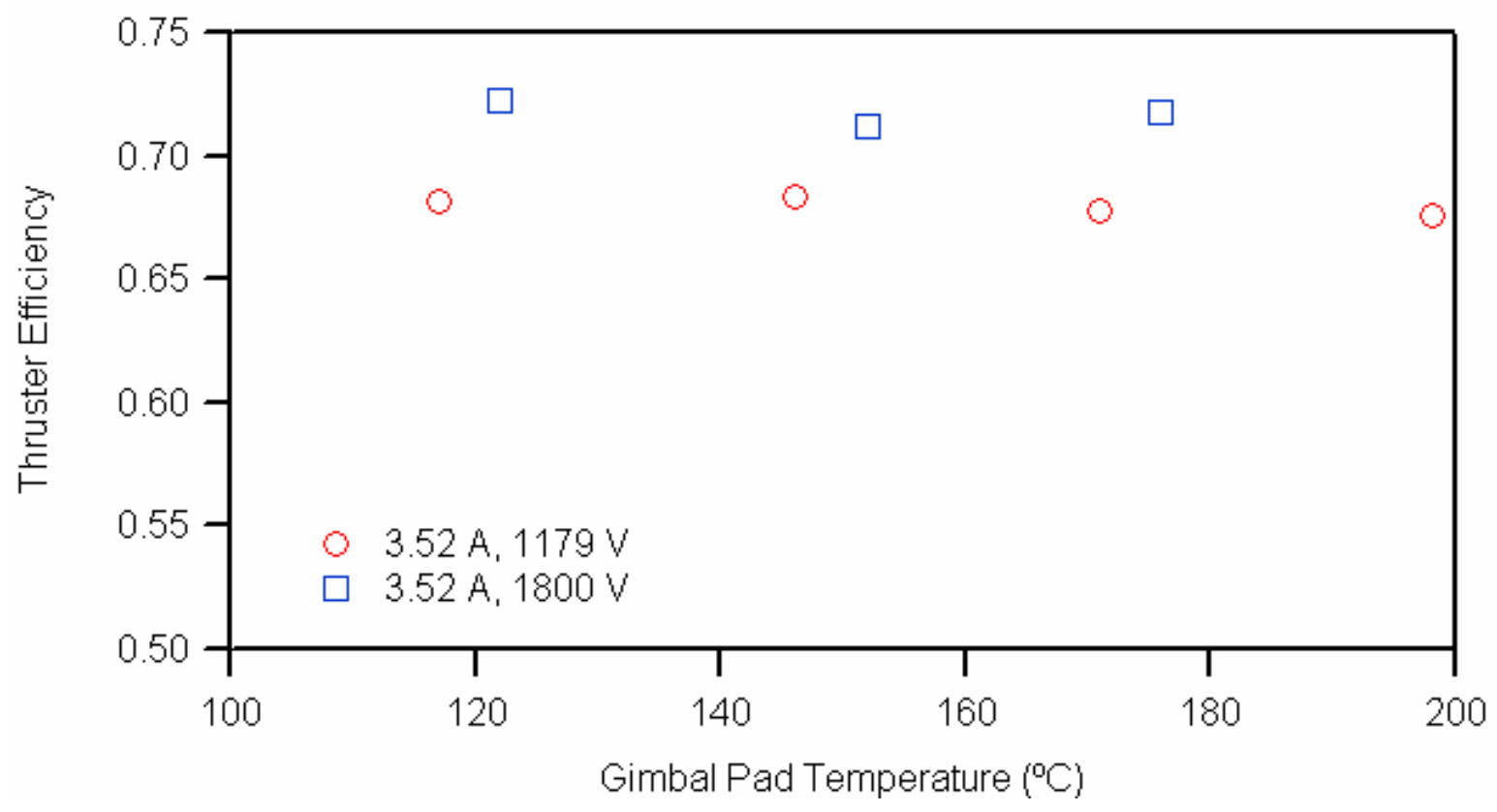

Figure 22. NEXT PM1 Efficiency Over the Thermal Range

of gimbal pad temperature in Figure 20. The lowest temperature points correspond to active cooling of the shroud. The points between 140 and $160{ }^{\circ} \mathrm{C}$ are at ambient conditions and the higher temperature points correspond to the high heat flux cases due to lamp heating. As seen from the data, the thrust remained constant over the thermal operating range tested. The specific impulse is shown as a function of gimbal temperature in Figure 21. The thermal range is the same as that for the thrust plot. As seen from the data the specific impulse remained constant over the thermal operating range tested. The thruster efficiency is shown as a function of gimbal temperature in Figure 22. The thermal range is the same as that for the thrust plot. Again a major driver for the thruster efficiency is the discharge power required to produce beam ions. There was no significant variation in discharge current or voltage for either of the two operating points over the range of thermal conditions tested. As a result the thruster efficiency did not vary over the thermal operating range tested. The thruster performance obtained over the range of environmental conditions tested is comparable to the performance observed during the pre-TDT and post-TDT functional testing and the acceptance testing performed at GRC.

\section{C.Post-TDT PM1 Inspection}

After the completion of the thermal development test and the subsequent functional test the NEXT PM1 thruster was removed from the vacuum facility and placed in a clean room at JPL. The thruster was inspected and disassembled in the clean room. The remaining thermocouple wires for the discharge chamber and the magnets appeared to have gotten hot but no obvious signs of arcing were found.

With two minor exceptions the thruster was found to be in good condition during the post-TDT inspection. One thermocouple punched through the discharge chamber mesh when the thermocouple was being removed. The small hole in the discharge chamber wall was repaired by spot welding a tantalum foil patch to the outside of the discharge chamber.

The thruster was hypotted during the inspection and the impedances between thruster components were found to be nominal with the exception of cathode common to anode. The cathode common to anode impedance had decreased over the course of testing. After removing and reinstalling the wiring at the back of the discharge cathode assembly, the impedance had increased by a factor of two. Because the voltage between the anode and cathode common is less than $30 \mathrm{~V}$ during normal thruster operation, even the lowest observed impedance results in negligible leakage current and is not a concern unless it continues to decrease during subsequent operation. 


\section{Recommendations}

The major recommendation from the thermal development test is that the gimbal pads be used as the reference temperature location for the thermal vacuum test. It is desirable to have the reference thermocouples on low voltage surfaces in order to avoid problems with high voltage stand off; therefore, the gimbal pads and the front mask were the two candidates for the reference temperature locations. Based on thermal development test data and modeling done at GRC the gimbal pads were determined to provide a better correlation with critical components-such as the magnets, propellant isolators and wire harnesses-than the front mask. Therefore the gimbal pads are recommended for the reference temperature location.

Based on the manner in which the cylindrical magnet thermocouple failed it was recommended that the plasma screen be modified to reduce or eliminate electron backstreaming through it. The NEXT project has replaced the plasma screen surrounding the cylindrical portion of the thruster with a solid shield. In addition the open area fraction has been reduced for the plasma screen over the conical section of the thruster.

\section{Summary}

The NEXT PM1 thruster was operated over a range of thermal conditions that bracket those that would be expected during a typical mission. Thermal conditions ranged from liquid nitrogen cooled shroud temperatures to $1000 \mathrm{~W}$ externally applied heat load. The thruster performed well during the thermal development test. The thruster performance parameters (thrust, specific impulse and thruster efficiency) were nominal over the range of environmental conditions the thruster was subjected to.

The data obtained during the test was useful for validating the thruster thermal model. The model predicts temperatures that are within $10{ }^{\circ} \mathrm{C}$ of those measured during the thermal development test for most thruster components. Based on the thermal modeling the gimbal pads were selected as the reference temperature location for the thruster. Data obtained during the highest heat flux operation case demonstrated a thermal margin of $88{ }^{\circ} \mathrm{C}$ for the magnets, $72{ }^{\circ} \mathrm{C}$ margin for the propellant isolator and $40{ }^{\circ} \mathrm{C}$ for the wire harness under the plasma screen. The exterior harness reached $189^{\circ} \mathrm{C}$ during operation at the high heat flux case.

Two minor issues were discovered during testing. One case resulted in adjusting the temperature limit for the exit wire harness jacketing from $150{ }^{\circ} \mathrm{C}$ to $200{ }^{\circ} \mathrm{C}$ for the thermal development test and subsequent environmental testing. Although the jacket material could survive operation at temperatures as high as $200{ }^{\circ} \mathrm{C}$, for the duration of the thermal development test and the subsequent environmental testing, it is not known if it can survive for longer durations at temperatures over $150{ }^{\circ} \mathrm{C}$. The NEXT project is investigating this issue. Possible solutions include determining if the jacket material can be rerated for long term operation at temperatures up to $200{ }^{\circ} \mathrm{C}$ or switching to another material rated for operation at a higher temperature. The second issue led to a design change to mitigate electron backstreaming through the plasma screen.

\section{References}

${ }^{1}$ M. J. Patterson, J. E. Foster, T. W. Haag, V. K. Rawlin, G. C. Soulas, R. F. Roman, "NEXT: NASA's Evolutionary Xenon Thruster," AIAA 2002-3832, $38^{\text {th }}$ AIAA/ASME/SAE/ASEE Joint Propulsion Conference and Exhibit, 7-10 July 2002, Indianapolis, Indiana.

${ }^{2}$ G. C. Soulas, T. W. Haag, M. J. Patterson, "Performance Evaluation of $40 \mathrm{~cm}$ Ion Optics for the NEXT Ion Engine," AIAA 2002-3834, 38 ${ }^{\text {th }}$ AIAA/ASME/SAE/ASEE Joint Propulsion Conference and Exhibit, 7-10 July 2002, Indianapolis, Indiana.

${ }^{3}$ S. W. Benson, M. J. Patterson, D. A. Vaughan, A. C. Wilson, B. R. Wong, "NASA's Evolutionary Xenon Thruster (NEXT) Phase 2 Development Status," AIAA 2005-4070, $41^{\text {st }}$ AIAA/ASME/SAE/ASEE Joint Propulsion Conference and Exhibit, 10-13 July 2005, Tucson, Arizona.

${ }^{4}$ W. A. Hoskins, F. C. Wilson, J. Polaha, L. Talerico, M. J. Patterson, G. C. Soulas, J. Sovey, "Development of a Prototype Model Ion Thruster for the NEXT System," AIAA 2004-4111, 40 ${ }^{\text {th }}$ AIAA/ASME/SAE/ASEE Joint Propulsion Conference and Exhibit, 11-14 July 2004, Fort Lauderdale, Florida.

${ }^{5}$ T. K. Phelps, S. Wiseman, D. S. Komm, T. Bond, L. R. Pinero, "Development of the NEXT Power Processing Unit," AIAA 2003-4867, 39 ${ }^{\text {th }}$ AIAA/ASME/SAE/ASEE Joint Propulsion Conference and Exhibit, 20-23 July 2003, Huntsville, Alabama.

${ }^{6}$ R. S. Aadland, J. Monheiser, E. A. Driscoll, F. Wilson, S. Benson, "Development Status of the NEXT Propellant Management System," AIAA 2004-3974, 40 th AIAA/ASME/SAE/ASEE Joint Propulsion Conference and Exhibit, 11-14 July 2004, Fort Lauderdale, Florida.

${ }^{7}$ D. A. Vaughan, "Gimbal Development for the NEXT Ion Propulsion System," AIAA 2005-3865, 41 ${ }^{\text {th }}$ AIAA/ASME/SAE/ASEE Joint Propulsion Conference and Exhibit, 10-13 July 2005, Tucson, Arizona. 
${ }^{8}$ J. Monheiser, R. S. Aadland, F. Wilson, "Development of a Ground Based Digital Control Interface Unit (DCIU) for the NEXT Propulsion System," AIAA 2004-4112, 40 ${ }^{\text {th }}$ AIAA/ASME/SAE/ASEE Joint Propulsion Conference and Exhibit, 11-14 July 2004, Fort Lauderdale, Florida.

${ }^{9}$ D. Oh, S. Benson, K. Witzberger, M. Cupples, “Deep Space Applications for NEXT: NASA's Evolutionary Xenon Thruster," AIAA 2004-3806, 40 ${ }^{\text {th }}$ AIAA/ASME/SAE/ASEE Joint Propulsion Conference and Exhibit, 11-14 July 2004, Fort Lauderdale, Florida.

${ }^{10}$ K. E. Witzberger, D. Manzella, D. Oh, M. Cupples, "NASA’s 2004 In-Space Propulsion Refocus Studies for New Frontiers Class Missions," AIAA 2005-4271, 41 ${ }^{\text {th }}$ AIAA/ASME/SAE/ASEE Joint Propulsion Conference and Exhibit, 10-13 July 2005, Tucson, Arizona.

${ }^{11}$ M. J. Patterson, "NEXT $\underline{S}$ tudy of Thruster Extended-Performance (NEXT STEP)," AIAA 2006-4664, 42 AIAA/ASME/SAE/ASEE Joint Propulsion Conference and Exhibit, 9-12 July 2006, Sacramento, California.

${ }^{12}$ J. R. Brophy, "NASA's Deep Space 1 Ion Engine," Review of Scientific Instruments, Vol 73, N0. 2, February 2002, pps. 1071-1078.

${ }^{13}$ J. R. Brophy, M. A. Etters, J. Gates, C. E. Garner, M. Klatte, C. John Lo, M. G. Marcucci， S. Mikes, G. Pixler, B. Nakazono, "Development and Testing of the Dawn Ion Propulsion System," AIAA 2006-4319, 42 ${ }^{\text {nd }}$ AIAA/ASME/SAE/ASEE Joint Propulsion Conference and Exhibit, 8-12 July 2006, Sacramento, CA.

${ }^{14} J$. L. Van Noord, "NEXT Ion Thruster Thermal Model," AIAA 2007-5218, 43 ${ }^{\text {rd }}$ AIAA/ASME/SAE/ASEE Joint Propulsion Conference and Exhibit, 8-11 July 2007, Cincinnati, OH.

${ }^{15}$ J. S. Snyder, J. R. Anderson, J. L. Van Noord, G. C. Soulas, "Environmental Testing of the NEXT PM1 Ion Engine," AIAA 2007-5275, $43^{\text {rd }}$ AIAA/ASME/SAE/ASEE Joint Propulsion Conference and Exhibit, 8-11 July 2007, Cincinnati, OH.

${ }^{16}$ D. A. Herman, G. C. Soulas, M. J. Patterson, "Performance Evaluation of the Prototype-Model NEXT Ion Thruster," AIAA 2007-5212, $43^{\text {rd }}$ AIAA/ASME/SAE/ASEE Joint Propulsion Conference and Exhibit, 8-11 July 2007, Cincinnati, OH.

${ }^{17}$ J. S. Miller, S. H. Pullins, D. J. Levandier, Y. Chiu, R. A. Dressler,"Xenon charge exchange cross sections for electrostatic thruster models," Journal of Applied Physics, V. 91, N. 3, pp. 984-992, 1 February 2002. 


\begin{tabular}{|c|c|c|}
\hline \multicolumn{2}{|c|}{ REPORT DOCUMENTATION PAGE } & $\begin{array}{l}\text { Form Approved } \\
\text { OMB No. 0704-0188 }\end{array}$ \\
\hline \multicolumn{3}{|c|}{ 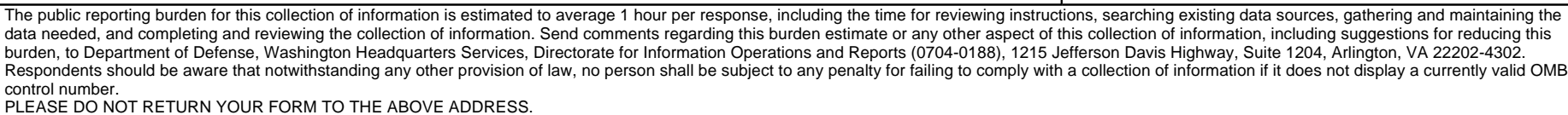 } \\
\hline $\begin{array}{l}\text { 1. REPORT DATE (DD-MM-YYYY) } \\
01-11-2010\end{array}$ & $\begin{array}{l}\text { 2. REPORT TYPE } \\
\text { Technical Memorandum }\end{array}$ & 3. DATES COVERED (From - To) \\
\hline \multirow{3}{*}{\multicolumn{2}{|c|}{$\begin{array}{l}\text { 4. TITLE AND SUBTITLE } \\
\text { Thermal Development Test of the NEXT PM1 Ion Engine }\end{array}$}} & 5a. CONTRACT NUMBER \\
\hline & & 5b. GRANT NUMBER \\
\hline & & 5c. PROGRAM ELEMENT NUMBER \\
\hline \multirow{3}{*}{\multicolumn{2}{|c|}{$\begin{array}{l}\text { 6. AUTHOR(S) } \\
\text { Anderson, John, R.; Snyder, John, S.; Van Noord, Jonathan, L.; Soulas, George, C. }\end{array}$}} & 5d. PROJECT NUMBER \\
\hline & & 5e. TASK NUMBER \\
\hline & & $\begin{array}{l}\text { 5f. WORK UNIT NUMBER } \\
\text { WBS } 346620.04 .05 .03 .13\end{array}$ \\
\hline \multicolumn{2}{|c|}{$\begin{array}{l}\text { 7. PERFORMING ORGANIZATION NAME(S) AND ADDRESS(ES) } \\
\text { National Aeronautics and Space Administration } \\
\text { John H. Glenn Research Center at Lewis Field } \\
\text { Cleveland, Ohio 44135-3191 }\end{array}$} & $\begin{array}{l}\text { 8. PERFORMING ORGANIZATION } \\
\text { REPORT NUMBER } \\
\text { E-17490 }\end{array}$ \\
\hline \multirow{2}{*}{\multicolumn{2}{|c|}{$\begin{array}{l}\text { 9. SPONSORING/MONITORING AGENCY NAME(S) AND ADDRESS(ES) } \\
\text { National Aeronautics and Space Administration } \\
\text { Washington, DC 20546-0001 }\end{array}$}} & $\begin{array}{l}\text { 10. SPONSORING/MONITOR'S } \\
\text { ACRONYM(S) } \\
\text { NASA }\end{array}$ \\
\hline & & $\begin{array}{l}\text { 11. SPONSORING/MONITORING } \\
\text { REPORT NUMBER } \\
\text { NASA/TM-2010-216914 }\end{array}$ \\
\hline \multicolumn{3}{|c|}{$\begin{array}{l}\text { 12. DISTRIBUTIONIAVAILABILITY STATEMENT } \\
\text { Unclassified-Unlimited } \\
\text { Subject Category: } 20 \\
\text { Available electronically at http://gltrs.grc.nasa.gov } \\
\text { This publication is available from the NASA Center for AeroSpace Information, 443-757-5802 }\end{array}$} \\
\hline
\end{tabular}

\section{SUPPLEMENTARY NOTES}

\section{ABSTRACT}

NASA's Evolutionary Xenon Thruster (NEXT) is a next-generation high-power ion propulsion system under development by NASA as a part of the In-Space Propulsion Technology Program. NEXT is designed for use on robotic exploration missions of the solar system using solar electric power. Potential mission destinations that could benefit from a NEXT Solar Electric Propulsion (SEP) system include inner planets, small bodies, and outer planets and their moons. This range of robotic exploration missions generally calls for ion propulsion systems with deep throttling capability and system input power ranging from 0.6 to $25 \mathrm{~kW}$, as referenced to solar array output at 1 Astronomical Unit (AU). Thermal development testing of the NEXT prototype model 1 (PM1) was conducted at JPL to assist in developing and validating a thruster thermal model and assessing the thermal design margins. NEXT PM1 performance prior to, during and subsequent to thermal testing are presented. Test results are compared to the predicted hot and cold environments expected missions and the functionality of the thruster for these missions is discussed.

\section{SUBJECT TERMS}

Ion thruster; Ion optics; Hollow cathodes

\begin{tabular}{|c|c|c|c|c|c|}
\hline \multicolumn{3}{|c|}{ 16. SECURITY CLASSIFICATION OF: } & \multirow{2}{*}{$\begin{array}{l}\text { 17. LIMITATION OF } \\
\text { ABSTRACT } \\
\text { UU }\end{array}$} & \multirow{2}{*}{$\begin{array}{l}\text { 18. NUMBER } \\
\text { OF } \\
\text { PAGES } \\
29\end{array}$} & \multirow{2}{*}{$\begin{array}{l}\text { 19a. NAME OF RESPONSIBLE PERSON } \\
\text { STI Help Desk (email:help@sti.nasa.gov) } \\
\text { 19b. TELEPHONE NUMBER (include area code) } \\
\text { 443-757-5802 }\end{array}$} \\
\hline $\begin{array}{l}\text { a. REPORT } \\
U\end{array}$ & $\begin{array}{l}\text { b. ABSTRACT } \\
U\end{array}$ & $\begin{array}{l}\text { c. THIS } \\
\text { PAGE } \\
\text { U }\end{array}$ & & & \\
\hline
\end{tabular}



